\title{
Formar e questionar? Os cursos de especialização em patrimônio cultural na década de 1970
}

\section{Flávia Brito do Nascimento ${ }^{1}$}

RESUMO: Este artigo tem por objetivo discutir os cursos de pós-graduação em patrimônio realizados na década de 1970, como resultado de políticas educacionais e culturais do Ministério da Educação e Cultura e do Ministério do Planejamento. Em 1974, 1976 e 1978 realizaram-se três cursos, em São Paulo, Pernambuco e Minas Gerais, respectivamente, estruturados como demanda do Ministério da Educação e Cultura e do Instituto de Patrimônio Histórico e Artístico Nacional (lphan) nos Encontros de Governadores de 1970 e 1971. A partir do Programa de Cidades Históricas (PCH), a demanda por profissionais especializados aumentou e o fomento aos cursos tornou-se responsabilidade do Iphan, em conjunto com universidades federais. Organizaram-se os Cursos de Restauração e Conservação de Monumentos e Conjuntos Históricos, os quais foram um importante fórum de debates sobre a prática e a teoria da preservação na década de 1970. Congregando professores e alunos com vivências e práticas diversas, eram ponto de encontro dos especialistas que tiveram nos cursos (aulas expositivas e práticas, viagens e bancas de defesa dos trabalhos finais) espaço para diálogo sobre as muitas práticas de preservação daqueles anos. Por meio de depoimentos orais, fontes primárias (documentos escritos) e bibliografia pertinente, acompanharemos as suas motivações, estruturas, agentes sociais, programas de aulas e debates.

PALAVRAS-CHAVE: Programa de Cidades Históricas - PCH. Cursos de Restauração. Patrimônio Cultural.

ABSTRACT: The purpose of this article is to discuss the graduate courses on heritage that were offered in the 1970s as a result of the educational and cultural policies of the Ministry of Education and Culture of Brazil. In 1974, 1976 and 1978, three different courses were offered in the states of São Paulo, Pernambuco and Minas Gerais, respectively. These courses were created by request from the Ministry of Education and Culture and the Institute of National Historic and Artistic Heritage (lphan) at the Governors' Meetings of 1970 and 1971. Demand for specialized professionals increased, motivated by the Program of Historic Cities (PCH), and Iphan along with Universities became responsible for providing support for these studies. In the
1.Professora

do Departamento de História da Arquitetura e Estética do Projeto da Faculdade de Arquitetura e Urbanismo da Universidade de São Paulo FAU USP. A pesquisa contou com o apoio da Fundação de Amparo à Pesquisa do Estado de São Paulo (Fapesp). E-mail: <flaviabn@usp.br> 
2. Prova escrita aplicada no IV Curso de especialização em conservação e restauração de monumentos e conjuntos históricos. Arquivo Central do Iphan, em Brasília.

3. Ver Lia Motta (2000). 1970s, a perceived shortage of professionals specialized in cultural heritage at various levels justified offering the courses, which were an important forum for discussions on preservation practice and theory. By gathering teachers and students with different backgrounds and experiences, the courses (consisting of lectures, activities, field trips and final projects presented to a board of examiners) provided the specialists with a space to dialogue on the different preservation practices of the time.

KEYWORDS: PCH/Program of Historic Cities. Restauration Courses. Cultural Heritage.

Introdução

Em 1981, a quarta edição do Curso de especialização em conservação e restauração de monumentos e conjuntos históricos, realizado em Salvador, aplicou a seguinte prova para a seleção dos candidatos:

a) onde o Decreto-lei n 25 de 30 de novembro de 1937 que organiza a proteção do patrimônio histórico e artístico nacional atende à Carta de Veneza?

b) onde há discordância?

c) quais os pontos a ressaltar em uma ou na outra e quais os em comum?

d) onde há desatualização nas duas?

e) quais os pontos a destacar em ambas?2

A prova versava sobre conceitos fundamentais de patrimônio no Brasil. Seu texto trazia um questionamento da legislação vigente, o Decreto-lei 25/37, e - colocava em contraste com os documentos internacionais como a Carta de Veneza. Os ventos da abertura política já sopravam e a primeira metade da década de 1980 seria significativa em mudanças conceituais para o patrimônio cultural, as quais pavimentariam o caminho para o Artigo 216 da Constituição Federal de 1988. A pressão da sociedade civil por novos posicionamentos do Estado e demandando direitos urbanos por meio das associações de bairro será sentida em muitos lugares desde a década de 1970. A preservação da diversidade cultural do país, do patrimônio urbano e os pedidos por uma atuação mais capilarizada dos níveis de governo no campo da preservação resultarão em ações inovadoras de preservação, sobretudo dos órgãos estaduais como Condephaat (São Paulo) e Inepac (Rio de Janeiro). A superação de conceitos "do belo e do velho" e a substituição pelo campo alargado da cultura pontuarão os cânones de preservação ${ }^{3}$.

Os cursos de especialização para arquitetos-preservadores já se realizavam desde 1974, e a quarta versão em Salvador/BA, a primeira dos "tempos de abertura", trazia as discussões e questionamentos dos últimos anos. A década de 1970 havia sido profícua em mudanças, estabelecidas a partir das diretrizes do regime militar para a cultura e o patrimônio. $\bigcirc$ interesse dos governos militares nos temas do patrimônio e da educação, no âmbito da "modernização 
conservadora autoritária"4, havia vertebrado novas políticas no campo. Para citar algumas, às quais retomaremos adiante: o Programa de Cidades Históricas (PCH) estava em curso, realizando inúmeras obras de restauração no Nordeste e depois no Sudeste; os órgãos estaduais de preservação do patrimônio cultural haviam sido criados e/ou tiveram sua atuação incrementada (Condephaat, Inepac, Fundarpe, por exemplo); experiências municipais de planejamento urbano trouxeram os debates da preservação para perto, como no caso do Rio de Janeiro, São Paulo e Recife; a Diretoria do Patrimônio Histórico e Artístico Nacional (DPHAN) transformou-se em Instituto do Patrimônio Histórico e Artístico Nacional (Iphan), o que deu mais autonomia à atuação do órgão. Finalmente, os cursos de especialização em restauração foram responsáveis pela formação de arquitetos para a preservação em cursos, em São Paulo, Recife e Belo Horizonte, que reuniram especialistas nacionais e internacionais, fomentando debates, questionamentos, além de formar novos quadros.

O enunciado da prova para o IV CECRE permite inferir que, em 1981 , a formação dos preservadores almejava aprofundar certos temas em ebulição. Pensar sobre as lacunas da legislação nacional, se comparadas às cartas internacionais, apresentava os limites da atuação do órgão federal e as expectativas de mudanças. A Carta de Veneza, citada no enunciado, já era uma velha conhecida, considerada pré-requisito de conhecimento para os que gostariam de enveredar pelo campo da preservação. As edições anteriores do Curso de Especialização em Restauração e Conservação de Monumentos e Conjuntos Históricos, que depois passou a ser conhecido pela sigla CECRE, desde 1974 trataram detalhadamente das legislações nacional e internacional ${ }^{5}$.

Quando acontece o curso de Salvador, a experiência de formação de arquitetos-especialistas já estava encaminhada. Em 1974, 1976 e 1978, realizaram-se três cursos, em estados do Brasil, estruturados como demanda do Ministério da Educação e Cultura e do Iphan nos Encontros de Governadores de 1970 e 1971. A partir do Programa Integrado de Reconstrução das Cidades Históricas do Nordeste, conhecido como Programa de Cidades Históricas $(\mathrm{PCH})$, com sua utilização para fins turísticos, o fomento aos cursos tornou-se prioridade. $\bigcirc$ sucesso da iniciativa, contando com professores e alunos de diversos lugares do Brasil, da América Latina e da Europa, levou à sua continuidade, fixando-se na Bahia até os dias de hoje, e, desde 2009, como curso de Mestrado Profissional em Conservação e Restauração de Monumentos e Núcleos Históricos. Na década de 1970, a percepção da escassez de mão de obra especializada em patrimônio cultural em diversos níveis justificou a organização dos cursos. Eles foram um importante fórum de debates sobre a prática e a teoria da preservação. Congregando professores e alunos com vivências e práticas diversas, eram ponto de encontro dos especialistas que tiveram nos cursos laulas expositivas e práticas, viagens e bancas de defesa dos trabalhos finais) espaço para debate das muitas práticas de preservação daqueles anos.
4. Para a discussão sobre o termo e sua pertinência, ver Rodrigo Patto Sá Motta (2014a, p. 11-12) e Daniel Aarão Reis , Rodrigo Patto Sá Motta e Marcelo Ridenti (2014).

5. Programas dos Cursos de Especialização em Restauração e Patrimônio de 1974, 1976, 1978. Arquivo Central do Iphan, em Brasília, e Arquivo do Iphan/SP. 
6. Agradeço a todos os que deram depoimentos valiosos sobre os cursos e o período: Lia Motta, Dina Lerner, Sylvia Fischer, Nestor Goulart Reis Filho, Jurema Kopke Eis Arnaut, Luiz Eduardo Pinheiro, Dora Alcântara, Carlos Lemos e José Luiz Mota Menezes.

7. Ver Sandra Corrêa (2012).

8. Ver Marly Rodrigues (2000); Lia Mayumi (2008); Paula Andrade (2012).

9. Currículo de Renato Soeiro no Programa do Curso de Restauração e Conservação de Monumentos e Conjuntos Históricos, s/d. Arquivo do Iphan/SP. Ver Augusto Carlos da Silva Telles (1977, p.22-23). Paula Andrade traz algumas informações sobre os professores e alunos a partir de entrevistas com Julio Katinsky. Ver Paula Andrade (2012, p. 37-38).

10. Cf. Augusto Carlos da Silva Telles (1977, p.23).
Este artigo focará a atenção nos três primeiros cursos de especialização organizados a partir de 1974. Por meio de depoimentos orais ${ }^{6}$, fontes primárias (documentos escritos) e bibliografia pertinente, acompanharemos as motivações, as estruturas, os agentes sociais (professores, alunos e instituições), programas de aulas e debates. O recorte na década de 1970 relaciona-se ao momento em que - PCH foi mais atuante. Embora tenha sido prorrogado e estendido na década de 1980, segundo Sandra Correa, o período de 1972 a 1979 - a primeira fase do $\mathrm{PCH}$, é a que melhor o representa como programa de governo7. A partir de 1980, passa a ter estratégias, características e funções distintas, sendo coordenado pelo Iphan e expandindo-se para outras regiões do país. Os cursos de 1974 (São Paulo), 1976 (Recife) e 1978 (Belo Horizonte) foram responsáveis por formar os quadros técnicos para a atuação nas inúmeras obras de restauração de monumentos em execução, primeiro no Nordeste e, depois, no Sudeste. Esses cursos trouxeram vigor ao campo e publicizaram a multiplicidade de visões sobre o patrimônio cultural naquela década de ditadura civil-militar no Brasil e amplo debate internacional.

O "culto ao passado", a "consciência nacional" e os cursos de pós-graduação em restauração de monumentos

O "Curso de 1974", como ficou conhecido, tornou-se um lugar de memórias de fundação das políticas de preservação no Estado de São Paulo, ajudando a forjar a identidade dos seus agentes e de suas práticas. As aulas ministradas pelo francês Varine-Bohan são frequentemente citadas pelo seu caráter inovador, responsáveis por mudar o pensamento cristalizado pelas práticas do "velho Iphan", o principal interlocutor de patrimônio no Estado até aquele momento8 ${ }^{8}$. Até o final da década de 1970, o patrimônio em São Paulo estava restrito à atuação do governo federal, e Luiz Saia, sucedendo a Mário de Andrade na direção da superintendência do instituto nos anos 1940, era a principal autoridade. A realização do curso em 1974 significou novos diálogos, com atores e agentes diversos, expondo a atuação consolidada do Iphan e trazendo temas ainda pouco explorados. Se Varine-Bohan fixou-se no imaginário como o responsável por abrir os caminhos, de modo geral, o curso (na relação entre os diversos professores e alunos) ajudou a minar barreiras.

As primeiras tratativas para a realização de cursos de especialização em patrimônio aconteceram ainda na década de 1960. Em 1965, teria ocorrido um curso na Faculdade de Arquitetura e Urbanismo da USP sobre patrimônio cultural, do qual participaram, como docentes, os arquitetos do Iphan, Augusto da Silva Telles e Renato Soeiro?. Pouco se sabe sobre as motivações e o programa do curso. Temos a informação de que "apesar de falhas na sua organização devido à inexperiência de seus coordenadores, foi ele de grande proveito"10. Nova tentativa de organização de curso de especialização aconteceu poucos anos 
depois, em 1969, quando o professor e diretor do Departamento de História da Arquitetura e Estética do Projeto da mesma FAU USP consultou Luiz Saia sobre o interesse na realização de um curso de "pós-graduação sobre restauro e conservação de obras de arte", a ser realizado pela universidade com a colaboração do Iphan ${ }^{11}$. As condições para a realização do curso de especialização tornaram-se mais propícias no ano seguinte, após o I Encontro de Governadores, realizado com o objetivo de "estudar a complementação de medidas necessárias à defesa do patrimônio histórico e artístico nacional". $\bigcirc$ resultado do encontro, segundo o documento final, foi aprovado por unanimidade e assinado pelo Ministro da Educação e Cultura Jarbas Passarinho, governadores e prefeitos presentes, em consonância com as diretrizes da Diretoria do Patrimônio Histórico e Artístico Nacional e pelo Conselho Federal de Cultura. A tônica da discussão levada a termo pelo presidente da então DPHAN, Renato Soeiro, e pelo Ministro da Educação e Cultura, Jarbas Passarinho, era a do compartilhamento das políticas de preservação com outros órgãos de governo, nos quais deveria se fomentar a criação e/ou fortalecer a atuação. $\bigcirc$ documento publicado como resultado das discussões do encontro, no seu primeiro item, preconizava a "inadiável necessidade da ação supletiva dos Estados e dos Municípios à atuação federal no que se refere à proteção dos bens culturais de valor nacional"12.

compartilhamento não era apenas das atribuições técnicas do patrimônio como valoração, preservação e promoção com a criação de órgãos locais de preservação fomentando a criação de legislações locais e destinando novas dotações de recursos. O transbordamento de funções atingiu as diversas esferas da atuação institucional. O Programa de Cidades Históricas, que virá na sequência dos encontros do início da década de 1970, nascerá fora do âmbito do patrimônio, como iniciativa do Ministério do Planejamento e Coordenação Geral, sendo um exemplo do que se viabilizará a partir dessas constatações. $\bigcirc$ mais simbólico dos valores institucionais do "patrimônio", os seus saberes, será também posto em xeque. Como mostraram diversos autores que trataram das políticas de fundação de patrimônio no Brasili3, o então Serviço do Patrimônio Histórico e Artístico Nacional será por muito tempo o protagonista nos estudos sobre a história da arquitetura e das cidades no Brasil. A "Academia Sphan", na expressão cunhada por Mariza Veloso Santos ${ }^{14}$, estudará, catalogará, protegerá e, sobretudo, legitimará a produção intelectual do campo de conhecimento, seja por meios de publicações (livros e revistas), seja por meio do ato legal do tombamento. Nas universidades, o estudo da chamada "arquitetura tradicional" se constituirá como campo de investigação somente nos anos 1940 e 1950 pelos professores da disciplina Arquitetura no Brasil, criada inicialmente no Rio de Janeiro. E, ainda assim, não era raro que o professor dessa disciplina fosse ligado ao Serviço do Patrimônio Histórico e Artístico Nacional, como é o caso de Paulo Santos no Rio de Janeiro, de Sylvio de Vasconcellos em Minas Gerais, Ayrton Carvalho em Recife e, por um breve período, Luiz Saia em São Paulo ${ }^{15}$.
11. Ofício de Nestor Goulart Reis Filho a Luiz Saia em 28 mar. 1969. Arquivo do Iphan/SP.

12. Cf. Compromisso de Brasília, documento do I Encontro dos Governadores, Secretários Estaduais da Área Cultural, Prefeitos Municípios Interessados, Presidentes e Representantes de Instituições Culturais, em abril 1970.

13. Ver Cecília Londres Fonseca (1997) e Márcia Chuva (2009).

14. Ver Mariza Santos Veloso (1996).

15. Sobre a docência de Ayrton Carvalho e Luiz Saia, ver Juliana Pereira (2012, p.103-108) 
16. Compromisso de Brasília (abr. 1970).

17. Idem.

18. Termo de Convênio entre o Ministério da Educação e Cultura e o Governo do Estado de São Paulo, 1973. Arquivo do Iphan/SP.

19. Parecer do conselheiro Luiz Saia ao Processo $\mathrm{n}^{\circ}$ 6927/70, da Secretaria de Estado de Cultura, Esportes e Turismo, em 13 mai. 1970. Arquivo do Iphan/SP.

20. Luiz Saia havia tentado entrar como docente na FAU/USP, sem sucesso. Diversos são os autores que mencionam esse ponto de sua biografia como algo significativo. Realizar o curso em conjunto com a universidade era algo importante. Depoimento de Nestor Goulart Reis Filho à autora em 23 set. 2015. Ver Carlos Roberto M. de Andrade et al. (2014, p. 87) e Fausto Sombra (2015).
As diretrizes do I Encontro de Governadores, realizado em abril de 1970, colocavam o ensino de história em destaque. $\bigcirc$ "culto ao passado" era "elemento básico da formação da consciência nacional" e, portanto, deveria ser estimulado nos seus diversos níveis (do elementar ao superior). No nível elementar deveriam ser estudados os monumentos representativos da tradição nacional, no nível médio, a disciplina de Educação moral e cívica cumpriria o papel de estudar o passado e, finalmente, nos cursos superiores, o exemplo da disciplina Arquitetura no Brasil era o que se esperava em termos de conhecimentos da formação nacional. Essa deveria expandir-se para os cursos de arte. Nos cursos ditos "não especializados", a disciplina Estudos brasileiros deveria dedicar-se também aos "bens culturais ligados à tradição nacional"16.

No texto do Compromisso de Brasília, os saberes do patrimônio serão compartilhados e ampliados por meio de cursos:

Para remediar a carência de mão-de-obra especializada, nos níveis superiores, médio e artesanal, é indispensável criar cursos visando à formação de arquitetos restauradores, conservadores de pintura, escultura e documentos, arquivologistas e museólogos de diferentes especialidades, orientados pelo DPHAN e pelo Arquivo Nacional os cursos de nível superior ${ }^{17}$.

$\bigcirc$ texto deixa entender que os cursos não seriam fornecidos pela DPHAN ou pelo Arquivo Nacional, mas orientados por eles. Ou seja, havia instituições mais preparadas para oferecer a formação e o ensino, que se tornavam parceiras na produção de conhecimento. Essa será a diretriz dos cursos de especialização em restauração de monumentos e conjuntos urbanos na década de 1970. Eles se realizarão como parceria do lphan e de órgãos estaduais de patrimônio com as universidades. Nos termos do convênio do curso de São Paulo, firmado em março de 1973, entre o Ministério da Educação e Cultura, Governo do Estado de São Paulo e Universidade de São Paulo, estava claro que:

modo pelo qual serão propostos os programas do referido curso, bem como os detalhes de sua organização, bem assim os detalhes de sua organização - que serão oportunamente submetidos aos órgãos superiores da Universidade de São Paulo - serão estabelecidos pela Diretoria do Patrimônio Histórico e Artístico Nacional e pelo Conselho do Departamento de História da Arquitetura e Estética do Projeto 18

arquiteto Luiz Saia, superintendente do Iphan em São Paulo, que se empenhou em levar o problema da formação de arquitetos ao Encontro de Governadores, em carta ao Ministro da Educação e Cultura, admite que a própria DPHAN sentia falta de especialistas na área e o quadro iria se agravar com a criação de órgãos regionais ${ }^{19}$. E, apesar de suas ressalvas para com a atuação da Faculdade de Arquitetura e Urbanismo, ela era o lugar mais adequado para realização curso ${ }^{20}$. Vale a citação do seu parecer como conselheiro do Condephaat sobre o convênio para o curso: 
Apesar da Faculdade de Arquitetura e Urbanismo da USP apresentar defeitos fundamentais na sua organização e orientação, o que entre outras razões a levou a um fracasso completo na iniciativa que tomou relativamente a um curso equivalente realizado anos atraz (sic) ao que se projeta realizar agora, parece que é a única Faculdade de Arquitetura que apresenta condições mínimas para realizar o pretendido ${ }^{21}$.

A DPHAN deveria fazer parceria com as universidades, obrigando-se a externalizar seus conhecimentos e abrir a atuação para a participação de outros agentes, notadamente do meio acadêmico. Com efeito, logo após o Encontro dos Governadores em Brasília é organizada uma publicação conjunta do Departamento de História da USP, do IAB-SP e do $4^{\circ}$ Distrito da DPHAN sobre o Compromisso de Brasília, na qual estão expostas as conclusões do encontro e um guia dos bens tombados pela DPHAN com fotos e verbetes dos monumentos, que haviam sido expostos durante o Encontro de Brasília, entre 1, 2 e 3 de abril de 1970. Da publicação consta, também, o convênio firmado entre USP, Governo do Estado de São Paulo, Ministério da Educação e Cultura e Diretoria do Patrimônio Histórico e Artístico Nacional para o Curso de Restauração ${ }^{22}$.

A diretriz ao ensino, e, em particular, ao ensino superior no Compromisso de Brasília, relacionava-se à política do governo militar no campo da formação universitária. Ou seja, ela não era isolada dos encaminhamentos do regime militar para a educação. Rodrigo Patto Sá Motta, em seu amplo estudo sobre as universidades e o regime militar, mostra os passos das mudanças na educação nesse período. $\bigcirc$ debate sobre as mudanças no ensino universitário era amplo antes do Golpe de 1964 e integrava as "reformas de base" de Jango. Com o governo militar, como contraponto às perspectivas socialistas e revolucionárias de antes, organizaram-se propostas para mudar o ensino, tornando-o mais técnico, eficiente e produtivo, em detrimento da tradição humanista. $\bigcirc$ debate estava posto tanto à direita, como à esquerda, e os rumos que tomaria a reforma só se delineariam no final da década de 1960 e nos anos 1970. Os diversos setores da sociedade que apoiaram o golpe militar em 1964 estavam de acordo de que as universidades precisavam enfrentar mudanças, dentre as quais, o fim do regime de cátedras e a ampliação do acesso ao ensino superior. A modernização conservadora implementada pelo regime militar no âmbito das universidades implicou na racionalização dos recursos, busca por eficiência, reforço da iniciativa privada, substituição ao sistema de cátedras e fomento à pesquisa e à pósgraduação 23 .

Após o período inicial de morosidade e fragilidade do MEC, em que as mudanças ficaram em compasso de espera, a partir de 1968, logo após o Al5, estruturou-se a reforma. Alguns decretos anteriores haviam estabelecido pontos importantes como a junção entre ensino e pesquisa, o estabelecimento de departamentos como subunidades das universidades, os colegiados para gestão das atividades e as atividades de extensão como forma de fazer chegar às comunidades os resultados de projetos de ensino e pesquisa. A reforma universitária
21. Parecer do conselheiro Luiz Saia ao Processo $\mathrm{n}^{\circ}$ 6927/70, da Secretaria de Estado de Cultura, Esportes e Turismo, em 13 mai. 1970. Arquivo do Iphan/SP.

22. Compromisso de Brasília (USP; IAB; DPHAN, s/d).

23. Rodrigo Patto Sá Motta (2014a). 
24. Ver Decretos no 53 e 252 de 1967 e Rodrigo Patto Sá Motta (2014a, p. 78-80 e 101-103).

25. Ver Rodrigo Patto Sá Motta (2014a, p. 106-109).

26. Ver Rodrigo Patto Sá Motta (2014b, p. 56).

27. Ver Rodrigo Patto Sá Motta (2014a, p. 255).

28. Ibidem, p. 255-257. saiu, finalmente, em 1968 sob a Lei n 5540, como resposta, dentre outras coisas, ao quadro de instabilidade política e como uma possível resposta à "segurança nacional" ameaçada diante da onda de protestos daquele ano. A expectativa de modernizar as instituições, acolher os excedentes (alunos aprovados no vestibular, mas que não tinham acesso à universidade por falta de vagas) e criando condições de trabalho e perspectivas de carreira era a de poder aplacar as forças oposicionistas e ganhar pontos políticos ${ }^{24}$.

A reforma universitária mudou os parâmetros do ensino superior no Brasil. Ela congregou pontos já estabelecidos em leis anteriores e uma de suas mudanças mais significativas foi pôr fim ao sistema de cátedras. Além disso, criou o vestibular unificado, o tempo integral e os departamentos. A regulamentação da carreira docente e dos regimes de trabalho ocorreu no final de 1968 e início de 1969. $\bigcirc$ ponto polêmico da possível privatização do sistema e da cobrança de mensalidade não chegou a ser efetivado diante da reação dos setores de oposição ${ }^{25}$. Para Rodrigo Motta, a reforma universitária é um dos exemplos das ambíguas e contraditórias ações do regime militar no campo universitário, em que constantemente tomaram-se ações repressivas ao lado de políticas apaziguadoras e jogos de acomodação. A reforma universitária foi impulsionada pela crise estudantil que procurava aplacar e se apropriou do projeto demandado pela esquerda antes do golpe militar ${ }^{26}$.

Dentre os diversos desdobramentos da reforma universitária de 1968 está o incremento da pós-graduação, o que nos interessa mais de perto. Após 1970 a onda modernizadora e desenvolvimentista cresceu e os Planos Nacional de Desenvolvimento I e II focaram a atenção na expansão e na aceleração dos investimentos científicos e tecnológicos, aumentando cursos e vagas de pósgraduação. De novo é Rodrigo Motta quem chama a atenção para as dificuldades do período muito repressivo, em que oportunidades de trabalho abriram-se para uns, ao passo que outros tiveram suas carreiras destruídas por razões políticas. A repressão intensiva dentro das universidades veio junto com carreiras docentes de altos salários e aumento do número de estudantes, além de maiores recursos para pesquisa e pós-graduação 27 .

A pós-graduação tornou-se uma prioridade. Era demanda antiga nos meios acadêmicos e viabilizou-se com as verbas do Fundo de Desenvolvimento Tecnológico (Funtec) e da Capes com a resolução do "parecer Sucupira", incorporado à reforma de 1968. Institui-se a separação entre pós-graduação strictu sensu (mestrado e doutorado com atividades de pesquisa e produção de conhecimento) e lato sensu (aperfeiçoamento e especialização). Os cursos estavam submetidos à aprovação e ao controle das agências públicas, de modo a garantir qualidade e atendimento aos preceitos estabelecidos. Já existiam alguns cursos de pós-graduação na década de 1960 (sobretudo nas áreas de agrárias, química e engenharias) e a expansão se deu exatamente no período mais repressivo do regime militar, entre 1970 e 1974. Embora nas humanas alguns cursos tenham sido criados, a ênfase maior da formação era nas áreas tecnológicas e de ciências naturais ${ }^{28}$. 
Em 1974, ano em que são criados 45 novos cursos de pós-graduação em várias áreas do conhecimento, num total de 403 cursos em todo território nacional, inicia-se o Curso de Conservação e Restauração de Monumentos e Conjuntos Urbanos, fornecido pela USP, juntamente com Iphan e Secretaria de Estado da Cultura de São Paulo. O interesse pela realização de cursos de preservação foi deliberado pelo Ministério da Educação e Cultura desde 1970 e pela USP desde o ano anterior, mas passaram-se quase quatro anos para que pudessem ter início.

primeiro "Curso de Especialização sobre Arquitetura Tradicional", 1974

No que se refere ao ensino de arquitetura, até 1960 os cursos de formação superior restringiam-se ao Rio de Janeiro, São Paulo, Minas Gerais, Rio Grande do Sul, Bahia e Pernambuco. Como especialização, houve um curso de urbanismo em nível de pós-graduação oferecido por pouco tempo pela Universidade do Distrito Federal, no Rio de Janeiro. Na década de 1960, surgiram quatro novos cursos de graduação em arquitetura nos estados do Paraná, Ceará, Goiás e Pará. Com a reforma universitária de 1968, a demanda pelo estabelecimento de um currículo mínimo dá lastro a amplas discussões sobre o caráter e os objetivos do ensino na área. A expansão do ensino superior, com a criação de diversos novos cursos, fenômeno comum às demais áreas do conhecimento, sobretudo em instituições privadas, levou ao número de 26 cursos de arquitetura em 1974 em todo território nacional. $\bigcirc$ patrimônio como formação básica do arquiteto durante a graduação constará do currículo mínimo somente a partir de $1994^{29}$.

Na década de 1970, o ensino de patrimônio histórico e artístico nacional ficava circunscrito às disciplinas de História da Arquitetura, e, em alguns casos, como na Universidade Federal do Rio de Janeiro - UFRJ, a Arquitetura no Brasil I e II. Rodrigo Melo Franco de Andrade, no clássico "Brasil: Monumentos históricos e arqueológicos", de 1952, esclarece que em 1945 foi criada a cátedra "Arquitetura no Brasil" na Faculdade Nacional de Arquitetura no Rio de Janeiro, e na sequência em Bahia, Pernambuco e Minas Gerais, todas naquele momento com professores interinos ${ }^{30}$. Como já mencionado, em diversos estados o professor da disciplina era funcionário do Patrimônio, como Ayrton Carvalho, Sylvio de Vasconcelos e Luiz Saia (por período curto). No Rio de Janeiro, Arquitetura no Brasil I e Arquitetura no Brasil || foram ministradas por muitos anos por Paulo Santos, Augusto da Silva Telles, seguidos por Dora Alcântara e Alfredo Britto. Os conteúdos específicos de patrimônio cultural eram mesclados aos de história da arquitetura no Brasil nos seus diversos períodos. Nas aulas de Dora Alcântara, seu marido, Pedro Alcântara, também um especialista na área e docente em outras faculdades, era frequentemente convidado a ministrar palestras ao final do curso sobre a preservação e suas políticas ${ }^{31}$.
29. Ver Ana Paula Farah (2012, p. 48-60).

30. Ver Rodrigo Melo Franco de Andrade (2012, p.180).

31. Depoimentos de Dora Alcântara (6 set. 2015), Lia Motta (9 set. 2015) e Dina Lerner (6 set. 2015) à autora. 
32. Ver Lia Calabre (2009, Capítulos 3 e 4).

33. Cf. Compromisso de Brasília (USP; IAB; DPHAN, s/d).

34. Memorando de Renato Soeiro ao Ministro da Educação e Cultura, em 21 jul.1971. Arquivo do Iphan/ SP.

35. Depoimento de Nestor Goulart Reis Filho à autora em 23 set. 2015.

36. Parecer do conselheiro Luiz Saia ao Processo $\mathrm{n}^{\circ}$ 6927/70, da Secretaria de Estado de Cultura, Esportes e Turismo, em 13 mai. 1970. Arquivo do Iphan/SP.

37. Documento de aprovação do convênio entre MEC, Secretaria de Estado de Cultura e USP para realização de curso de restauração para arquitetos, Conselho Universitário da USP, 19 mai.1970. Arquivo do Iphan/SP.

38. "Convênio que entre si fazem do Ministério da Educação e Cultura e o Governo do Estado de São Paulo, através de sua Secretaria de Cultura Esportes e Turismo". Arquivo do Iphan/SP.

39. Ofício de Jarbas Passarinho ao Governador do Estado de São Paulo, Dr. Alceu Sodré em 02 abr. 1971. Arquivo do Iphan/SP.
A demanda de 1970 do Ministério da Educação e Cultura para a formação nessa área fundava-se no interesse pela cultura e pelo patrimônio cultural como estratégicos para o governo. Jarbas Passarinho dará atenção especial ao tema e o Plano de Ação Cultural - PAC estruturará financiamentos de eventos culturais, patrimônio, atividades artísticas e culturais, além da captação de pessoal. O MEC terá sua estrutura administrativa reformulada em 1970, por meio do Decreto $n^{\circ}$ 66.967, e a Divisão do Patrimônio Histórico e Artístico Nacional DPHAN torna-se o Iphan ${ }^{32}$. Sobre preservação, história, nacionalidade e o papel do Estado, a citação de Jarbas Passarinho em publicação de USP, IAB e DPHAN de 1970 a respeito do Encontro de Governadores demonstra um dos lugares em que se colocava o patrimônio: "Cabe a nós, representantes do povo, em cujo nome exercemos o poder, fazer com que o orgulho nacional pela nossa História se manifeste, mais acentuadamente, na manutenção de nossos documentos e na conservação de nossas relíquias" ${ }^{\prime 3}$.

Logo após o Encontro de Salvador iniciam-se trocas de ofícios para a organização do curso em São Paulo ${ }^{34}$. O professor Nestor Goulart Reis Filho, como dito anteriormente, iniciou em 1969 comunicação com o lphan para a proposta de um curso. No ano seguinte, esteve presente ao Encontro de Governadores em Brasília levando seu livro "Quadro da Arquitetura no Brasil", recém-lançado naquele mesmo ano, organizado a partir de artigos publicados na imprensa ${ }^{35}$. A efetivação do curso se dará por meio da articulação entre três esferas: a Secretaria de Cultura e Esportes do Estado de São Paulo, o Iphan e a USP. Ainda em 1970, Luiz Saia na qualidade de conselheiro do Condephaat dá parecer favorável à realização do curso, alegando que São Paulo, além do Rio de Janeiro, era o único lugar em que se encontrava a documentação gráfica do Iphan, indispensável para a realização do curso. Ademais, para a parte prática, nos arredores de São Paulo estavam disponíveis diversos exemplares de bens tombados restaurados pelo Iphan no estado, ou seja, por ele próprio Luiz Saia ${ }^{36}$.

Também em 1970, o curso é aprovado pelo Conselho da USP37. Em 1971, circulam minutas do convênio entre as Secretaria de Cultura e de Esportes de São Paulo e o Ministério da Educação e Cultura para realização na FAU/USP do curso de Especialização sobre arquitetura tradicional especialidade no que se referente aos trabalhos de restauração, ambientação e aproveitamento de monumentos. $\bigcirc$ desembolso de recursos seria da Secretaria de Estado de Cultura de São Paulo, na ordem de trezentos mil cruzeiros, para o "custeio de viagens, manutenção e remuneração de professores, contratação de serviços necessários à organização e funcionamento do curso, inclusive sua secretaria e tarefas de registro e reprodução de aulas" ${ }^{\prime 3}$. $O$ repasse de verbas seria para o diretor da Faculdade de Arquitetura e Urbanismo que o gerenciaria. $O$ curso deveria acontecer em 1972, mas não se sabe por que razão, só aconteceu quase dois anos depois, em 1974. O empenho do Ministro Jarbas Passarinho era no sentido de anunciar o curso no II Encontro de Governadores, em Salvador ${ }^{39}$. Esse encontro, acolhido e financiado pelo governador da Bahia Antônio Carlos Magalhães, reuniu na capital 
do estado participantes de todo o Brasil. Os temas discutidos no ano anterior, em Brasília, ganharam mais vigor, e a formação de quadros profissionais foi discutida na $5^{a}$ Sessão Plenária - Pesquisa, Estudo, Análise e Divulgação dos Bens de Valor Cultural. $\bigcirc$ estudo apresentado por Américo Simas Filho, do Conselho Estadual de Cultura da Bahia e da Faculdade de Arquitetura da Bahia, recomendava para o ensino superior:

4 - Que seja criado Curso de Pós-Graduação para especialização de profissionais de nível universitário, necessárias às diferentes tarefas de defesa do patrimônio histórico, artístico, arqueológico e natural, com os devidos cuidados e dentro dos padrões aceitos pela UNESCO e o IPHAN;

$(\ldots)$

6 - Que os cursos anteriormente mencionados sejam realizados segundo um sistema de rodízio que contemple, sucessivamente, as regiões do país que tenham Universidade e apreciável acervo de bens culturais;

7 - Que sejam criados nas Universidades situadas em regiões detentoras de valioso legado cultural, Seminários de Restauração, no propósito de divulgar aspectos importantes a defesa do patrimônio histórico, artístico, arqueológico e natural40.

A primeira versão da exposição de motivos do curso de São Paulo incluía além de arquitetos, historiadores da arte e arqueólogos, dependo de seu currículo. Ao final, o curso realizou-se na FAU/USP para arquitetos, com foco nos temas e problemas do dito patrimônio da "pedra e cal". $\bigcirc$ objetivo era "formar especialistas para o atendimento das unidades dos serviços de proteção do patrimônio histórico e artístico do País". O programa foi organizado de modo que a experiência prática dos quase 40 anos de atuação do Iphan e de seus técnicos servisse como paradigma de formação a novas gerações. Era com o muito que se havia feito em termos práticos para preservação do patrimônio histórico e artístico nacional que se iria organizar o curso. $O$ baluarte do conhecimento técnico do Iphan era Lucio Costa que, na qualidade de consultor, foi convidado a emitir parecer sobre o conteúdo programático do curso ${ }^{41}$. Nesse parecer, destaca que deveria ser considerada a possibilidade de realização de uma obra de restauro no decorrer do curso, de modo que os alunos pudessem acompanhar sua execução. Do trabalho final dos alunos deveria constar pelo menos um levantamento completo, pesquisas e fontes bibliográficas, além de documentação fotográfica. Além disso, a fotografia era de suma importância, pois o arquiteto-restaurador deveria ser um fotógrafo ${ }^{42}$. A experiência internacional era importante, mas subsidiária ao perfil prático que se pretendia dar à especialização, em que as aulas teóricas eram mescladas com as viagens de campo e finalizadas com a elaboração de um projeto de restauro. Costa chega a citar a experiência do México na área como um bom exemplo a ser conhecido pelo Brasil. Mas, me parece que o efeito não planejado do curso foi o sucesso e o impacto no pensamento de patrimônio que tiveram as aulas de professores estrangeiros como as do francês Varine Bohan, museólogo e historiador da arte, para muito além dos temas do patrimônio edificado.
40. Ministério da Educação e Cultura (1973, p. 320).

41. Parecer de Lucio Costa sobre o Curso de Restauração e Conservação. Arquivo do Iphan/SP.

42. Sobre a importância e o lugar da fotografia no patrimônio histórico e artístico nacional, ver Eduardo Costa (2015). 
43. Com a mudança do curso de Arquitetura para a Cidade Universitária era preciso dar uma destinação educativa ao edifício. $\mathrm{O}$ projeto da pós-graduação deu a destinação necessária ao casarão, como já havia mencionado desde 1969 o Professor Nestor Goulart Reis Filho.

44. Depoimento de Sylvia Fischer à autora em 29 set. 2015. A lista de alunos merece ser divulgada: de São Paulo estavam Antonio Luiz Dias de Andrade, Benedito Lima de Toledo (FAU USP), Antonio das Neves Gameiro (IPHAN), Bernardo José Castello Branco, Carla Milano Benclowicz, Carlos Lemos (FAU USP), Celso Dalprat Franco, Eideival Bolanho, Gustavo Neves da Rocha Filho (FAU USP), Julio Abe, Luiz Carlos de Moura Azevedo, Maria Estela Prandini, Murilo Marx, Nelson Brotto, Rosa Maria Braga Puchala, Sylvia Ficher, Theresa Katinsky; do Nordeste constam Antonio Luciano de Lima Guimarães (Fortaleza/CE), Francisco de Deus Barbosa (Fortaleza/ CE), Geraldo Gomes da Silva (Recife/PE), José Luiz da Conceição (Aracaju/SE), Maria Adriana A. Couto de Castro (Salvador/BA), Maria Eveline Vasconcelos (Fortaleza/CE), Paulo Feijó (Fortaleza/CE); da região Norte somente Roberto de La Roque Soares de Belém/ PA e Domingos Linheiro (São Luiz/MA); do Centro Oeste Doracy Lemes (Goiânia/GO) e, finalmente, do Sul compareceu Osmar Marcos Grubba de Florianópolis/SC. Arquivo do Iphan/SP.
Afinal, o curso iniciou-se, após novos adiamentos devidos à dificuldade de divulgação das inscrições, em 17 de junho de 1974, com aulas todas as tardes (de 14 às 18h) na atual sede da pós-graduação em Arquitetura e Urbanismo da USP, situada à Rua Maranhão - um palacete eclético da família Penteado cedido à universidade com a condição de abrigar usos educativos ${ }^{43}$. $\bigcirc$ curso, que na divulgação de 1974 já recebeu a nomenclatura de "Curso de Restauração e Conservação de Monumentos e Conjuntos Arquitetônicos", teve ampla divulgação por meio de ofícios aos governadores de estado, prefeitos, às universidades e diretorias locais de patrimônio já estabelecidas como as do Paraná e de Minas Gerais (para citar os destinatários dos convites que localizamos). Matricularam-se 30 alunos de todo o Brasil, com experiências diversas no campo patrimonial, sendo 15 indicados pelo Iphan, 10 pela Secretaria de Estado de Cultura, Esportes e Turismo de São Paulo e 5 pela USP. Sylvia Ficher, aluna do curso, destacou a riqueza de experiências pessoais e vivências que o curso proporcionou, além da sua alta qualidade ${ }^{44}$.

Após algumas versões, o programa final tinha uma estrutura complexa, mesclando blocos de aulas teóricas, com viagens e aulas práticas. $\bigcirc$ curso era organizado em cinco grupos de disciplinas: 1) Teoria da Conservação (Teoria da Conservação e Legislação, Noções de Museologia e Arqueologia, Experiência Estrangeira, Seminário de política de Proteção); 2) Técnicas de Restauração (Processos de Restauração, Experiência Nacional e Estrangeira, Restauro de Pintura, Escultura e Talha); 3) Técnicas Auxiliares de Restauração (Técnicas de Pesquisa e Documentação, Documentação e Análise de Conjuntos Urbanos, Administração de Programas); 4) Projetos de Restauração (edifícios, conjuntos urbanos, paisagismo, adaptação de edifícios a museus); 5) Seminário de Formação Brasileira e Regional. Além disso, estavam previstos estágios de viagens às regiões Centro-Sul e NorteNordeste.

O núcleo maior de docentes era a "prata da casa" do Iphan. As aulas teóricas e práticas de restauração eram dadas por técnicos de várias regiões: da sede no Rio de Janeiro, vieram Renato Soeiro, Augusto da Silva Telles, Alcides da Rocha Miranda e Edson Motta; das regionais, Ayrton de Carvalho, Diógenes Rebouças, Godofredo Filho, José Antônio de Mello e Fernando Leal. O Seminário de Formação Brasileira e Regional teve aulas com pensadores sociais brasileiros e nele discutiram história e formação do Brasil. Para esse módulo de 20 horas/aula foram convidadas diversas personalidades do meio intelectual brasileiro, como Afonso Arinos, Fernando Novais, Carlos Guilherme Mota, Francisco Iglésias, entre outros.

Ulpiano Bezerra de Meneses, professor do Museu de Arqueologia e Etnologia da USP, foi um parceiro importante do curso. Ministrou a disciplina Noções de Museologia e Arqueologia, abordando temas como pesquisa interdisciplinar, cultura material, valorização do patrimônio arqueológico e abordagens antropológicas do "bem natural" e do "bem cultural". Foi por seu intermédio que se chegou ao Professor Varine-Bohan, cujas aulas causaram tamanho impacto nos alunos. VarineBohan iniciava o programa do curso propondo uma nova definição de patrimônio, 
da qual seguia pelas estruturas internacionais, legislação, conservação, da conservação à restauração, chegando nas tendências de museologia e finalizando com o "patrimônio como fator positivo na satisfação de necessidades" e nos novos modelos para sua utilização ${ }^{45}$. Segundo Paula Andrade ${ }^{46}$, Hugues de Varine-Bohan esteve no Brasil entre 1966 e 1967 numa missão para o desenvolvimento de museus na América Latina, quando conheceu Ulpiano Bezerra de Meneses lque the serviu como guia em São Paulo), Rodrigo Melo Franco de Andrade, e percorreu estados como Minas Gerais, Salvador e Recife.

Além de Varine-Bohan, o francês Michel Parent e o português Alfredo Viana de Lima compuseram o quadro docente estrangeiro ${ }^{47}$. Fernando Peres, diretor do Serviço de Monumentos Nacionais de Portugal, e Graziano Gasparini, arquiteto venezuelano, foram convidados, mas não puderam comparecer. Em comum, os três professores estrangeiros que vieram compartilhavam o fato de terem sido consultores no Brasil na década de 1960, estabelecendo conhecimentos e laços profissionais com a "gente do patrimônio". Parent e Viana de Lima eram já conhecidos por aqui pelas importantes consultorias por intermédio da Unesco sobre o patrimônio nacional e planos diretores (no caso de Viana de Lima sobre Ouro Preto, São Luís e Alcântara) ${ }^{48}$. Estavam afinados com o discurso e os protagonistas da preservação no Brasil, sendo financiados pelo governo brasileiro para realizar tais trabalhos. Os objetivos da vinda de professores estrangeiros eram "dar uma noção universal dos problemas de proteção ao patrimônio", "confrontar as normas internacionais com a legislação local" e "aperfeiçoar as técnicas de restauração praticadas no Brasil onde ela se mostrasse deficitária"49. Ou seja, colocar o trabalho feito aqui em perspectiva internacional, discutindo a legislação e melhorando em "alguns pontos".

programa das disciplinas do curso revela a preocupação de seus organizadores em abarcar o campo do patrimônio (note-se que na documentação aparece a nomenclatura patrimônio cultural) na sua interdisciplinaridade e na multiplicidade de opções de trabalho. Embora dedicado ao patrimônio edificado e à sua restauração, os temas das aulas no decorrer do curso foram do museu à cidade, passando por artefato e legislação, além de discutir conceitos e metodologias. Temas novos na década de 1970, como documento-monumento, propostos pela Nova História francesa e a legislação internacional como Carta de Veneza e as Normas de Quito constavam dos programas de curso e foram objeto das aulas e colocavam em discussão o Decreto-lei n² $5 / 37$, o qual institui o patrimônio no Brasil. Esse foi um tema recorrente nos cursos da década de 1970 e que persistiu nos anos 1980, como pudemos ver na prova para o IV CECRE. Seria o decreto-lei sobreposto ou ultrapassado diante de novas recomendações e legislações? Como seria a ação supletiva dos estados e municípios? Como estabelecer novas normas para os órgãos locais e de que maneira elas ajudariam na criação de um sistema nacional de patrimônio? Eram temas da ordem do dia e em franco estabelecimento naquele momento, que ecoaram nos cursos de especialização da década de 1970.
45. Ver Hughes de VarineBohan (1975).

46. Ver Paula Andrade (2012, p. 50-53).

47. Todos receberam honorários no valor de mil dólares para ministrar as aulas, além das passagens e despesas com deslocamentos e alimentação. Deveriam estar à disposição para o curso por um período de 20 dias.

48. Sobre as missões da Unesco e Michel Parent, ver Claudia Leal (2008). Sobre Viana de Lima, ver Arthur Ramalho (2015).

49. Curso de Restauração e Conservação de Monumentos e Conjuntos Históricos, 1974, Arquivo do Iphan/SP. 
50. Curso de Restauração e Conservação d e Monumentos e Conjuntos Históricos. 1974, Arquivo do Iphan/SP.

51. Idem.

52. Ver o trabalho de Cristiane Gonçalves (2007).

53. Ver José Luiz da Conceição (1974).

54. Ibidem, p. 11.

55. Ibidem, p. 25.
No que se refere aos saberes da restauração, a convicção do Iphan era mais explícita. Os 35 anos de atuação no patrimônio haviam formado corpo técnico experiente na salvaguarda das características estético-estilísticas dos bens selecionados como patrimônio nacional. Era para que eles se perpetuassem às gerações futuras que os esforços haviam sido envidados e que os cursos tinham sentido. As aulas de restauração ledifícios, conjuntos urbanos, paisagismo e adaptação de edifícios a museus) eram o ponto nevrálgico do curso. A formação dos alunos nessas aulas passava por "transferir aos alunos a experiência do Instituto do Patrimônio Histórico e Artístico Nacional nos seus 35 anos de atividades" 50 . Nesse sentido, era importante que "(...) sempre que possível, a matéria será ministrada pelo próprio arquiteto que conduziu as obras ou que tenha colaborado na elaboração das soluções aplicadas"51.

Diante dos conhecimentos adquiridos com o curso, as aulas teóricas de restauro (visitas de campo) tiveram seu impacto, pois problematizavam conceitos e práticas, colocando muitas vezes em xeque as restaurações apresentadas seja em aula, seja em campo. Como outros autores já apontaram, as práticas de restauro em São Paulo de Luiz Saia, o coordenador do curso de especialização, eram apoiadas em retornos a estados "primitivos" e inferências a partir de fotografias ${ }^{52}$. José Luiz da Conceição, aluno do curso, representante da Secretaria de Obras Públicas de Sergipe, escreve em relatório de viagem a Minas Gerais, em setembro de 1974, que a máxima das aulas teóricas era a do "cada caso é um caso". Embora tivesse o tempo todo percebido que tal afirmação era verdadeira, verificava que o ponto em comum das obras de restauro visitadas era, na verdade, a volta do "monumento desfigurado ao estado primitivo". Sempre que o projeto de restauro se aproximava mais do original, mais a solução arquitetônica de salvamento do monumento se juntava ao ideal. O Museu do Ouro em Sabará, restaurado pelos pioneiros do Iphan (Rodrigo Melo Franco de Andrade, Lucio Costa, Renato Soeiro e José Reis) Ihe foi particularmente intrigante. A restauração à idêntica dos balaustres da fachada sem a diferenciação entre os novos e os velhos trouxe a admiração da turma no curso ${ }^{53}$. Mas, para o aluno ficava a pergunta: "Não se deveria deixar aparecer de alguma maneira a peça que serviu de amostra? Cada caso é um caso. É duro entender a queima-roupa esses critérios" $"$.

As dificuldades do aluno eram entender como e quando aplicar os critérios tão relativos do "caso a caso". Como distinguir o "espúrio do acréscimo participante"? Como identificar a necessidade de fechamento de arcos na lgreja do Carmo de Serro ou o deslocamento da torre sineira da lgreja do Carmo de Diamantina, por exemplo? A suposta "evidência fotográfica" não pareceu ser suficiente para as decisões de restauro. $\bigcirc$ aluno conclui o relato da viagem a Minas, afirmando que no seu decorrer a polêmica havia se instaurado e que os critérios "tão misteriosos" das obras de restauro haviam se tornado menos abstratos $^{55}$.

A polêmica maior viria, ainda, com a viagem ao Nordeste. $\bigcirc$ mesmo aluno faz a constatação do "critério totalmente ultrapassado desde a prática até a 
ideologia aplicado à restauração nas Igrejas da Sé e do Colégio da Graça em Olinda"56. E denuncia, "O que ali está acontecendo é a uma destruição de dois monumentos que representam uma sequência de documentações de várias épocas" 57 .

E, em um tom de desabafo, encerra o relatório: "Como então se pode imaginar a visão de tantas gerações destruídas tão bruscamente? Não estarão eles com esses pensamentos, executando os monumentos como documentos?".

Mobilizando conceitos de Camilo Boito e Gustavo Giovannoni, os quais não se sabe apresentados por qual professor no curso de especialização, José Luiz da Conceição evoca os princípios da distinguibilidade e arrisca dizer que o que estava se aplicando na Sé de Olinda era a teoria de Violet-le-Duc, com a reconstrução e a perda tołal de autenticidade dos monumentos. E questiona: "será que com a volta ao estado primitivo aqueles monumentos significarão documentos valiosos de um povo?"58. São questões que reverberarão nos cursos seguintes dos anos de 1976 e 1978. O debate sobre o patrimônio cultural e as práticas de restauração será ainda mais polêmico, seja pelos ventos de abertura políitica diante da dissenção do regime militar, seja porque o alargamento de conceitos e a troca de ideias que o curso de especialização de 1974 havia proporcionado se espalharam, ecoando nas práticas de restauro, nas repartições e nas mentes nos anos subsequentes.

O Nordeste, o PCH e o patrimônio como profissão: II Curso de Restauração, 1976

Segundo depoimentos, o entusiasmo de Luiz Saia com a especialização foi contagiante. Participou ativamente do curso, estando presente nas aulas, acompanhando as viagens de campo, e terminou a experiência com a convicção de que iria finalmente poder dedicar-se ao ensino. Mas morreu no ano seguinte, em 1975, sem concretizar seu plano profissional ${ }^{59}$. O curso, que foi considerado muito bem sucedido, ficou sem poder realizar-se novamente em São Paulo.

No mesmo ano, 1975, começaram as iniciativas para o próximo curso de especialização em restauração, que foi realizado em Pernambuco em 1976. Das primeiras proposições para um curso nesses moldes, até 1976 quando ocorre o segundo curso, mudanças importantes aconteceram, tanto no âmbito do ensino, como no campo das políticas de patrimônio. Na estruturação inicial para os cursos de pós-graduação, ainda em 1970, a FAU USP, na pessoa do Professor Nestor Goulart Reis Filho, e Luiz Saia moveram-se velozmente e o articularam no momento político propício para tal, em que o Condephaat e o Governo do Estado de São Paulo aportaram recursos e viabilizaram o convênio com o governo federal e a Universidade de São Paulo. A legitimidade de Luiz Saia junto à área central do Iphan deu ao curso a direção teórica e prática necessária, garantido que fosse uma formação de acordo com os cânones institucionais. No contexto nacional, Saia e as casas bandeiristas eram importantes peças da articulação discursiva da
56. José Luiz da Conceição (1974).

57. Idem

58. Idem.

59. Depoimento de Nestor Goulart Reis Filho à autora em 23 set. 2015. 
60. Ver Sandra Correa (2012).

61. Ministério da Educação e Cultura (1973, p. 320). geração de Rodrigo Melo Franco de Andrade e Lucio Costa. Mas a força do barroco e do colonial como imagens do passado nacional estava nas obras de Minas Gerais, Bahia ou Pernambuco. E, portanto, na viabilização da especialização, a Universidade de São Paulo e a Faculdade de Arquitetura e Urbanismo (FAU) fizeram a diferença. Apesar das ressalvas de Saia à FAU, já apontadas anteriormente, a oportunidade de realizar o curso em São Paulo não foi perdida. Ocorre que a FAU já tinha regimento para pós-graduação desde 1969, logo após a reforma universitária. A portaria GR.885 de 25.8.1969 organizava os cursos na faculdade de arquitetura e vinha de então a intenção de constituir um programa para a FAU e dar uso para a sede no bairro de Higienópolis.

Em 1975, o Programa das Cidades Históricas estava em andamento e entrando em uma nova fase, segundo Sandra Correa. $\mathrm{O} \mathrm{PCH}$ integrava-se às políticas do governo militar de desenvolvimento urbano e regional associadas ao crescimento econômico e à tentativa de reversão dos desequilíbrios regionais do país. O programa era gerido pelo Ministério do Planejamento e Coordenação Geral por meio de sua Secretaria Executiva instalada na Delegacia Regional do Miniplan em Recife. Em pouco tempo, o programa firmou convênios com quase todos os estados envolvidos para a consubstanciar suas metas de preservação de monumentos históricos com vistas ao seu aproveitamento econômico, gerando renda na região nordeste. Problemas com a estrutura do Iphan, a execução dos projetos, interesse dos estados no tema, levaram a que, em 1975, o economista Henrique Oswaldo fosse convocado pela Presidência da República para avaliar o programa, assumindo a sua coordenação geral. $O$ papel do Iphan vai se ampliando no $\mathrm{PCH}$ ao longo do tempo, bem como é percebida a necessidade de maior participação dos estados na elaboração dos projetos e na construção da política de patrimônio. Um grupo de trabalho é instituído e, composto por membros do Iphan, Embratur, Miniplan e Comissão Nacional de Regiões Metropolitanas e Política Urbana, avaliava os projetos e propostas do $\mathrm{PCH}^{60}$.

No que se refere ao curso de especialização de 1976, uma primeira mudança é que ele foi incorporado aos propósitos do PCH, articulando-se ainda mais diretamente aos interesses das políticas de preservação do governo federal. $\mathrm{O}$ PCH foi um programa, inicialmente, para investimento de recursos nas cidades históricas da região nordeste do Brasil, visando a restauração de bens imóveis para aproveitamento turístico. A engrenagem de preservação que se estruturará nesse período vai organizar, nos moldes do planejamento governamental, todas as áreas de atuação ao redor dos mesmos interesses. O foco das políticas eram as restaurações nas cidades históricas do Nordeste e é em torno delas e de seus interesses que os esforços se voltarão. Como, nesse momento, o Nordeste era o alvo das políticas, era de se esperar que o curso mudasse sua base. Note-se que o rodízio de sedes do curso estava sugerido desde o II Encontro de Governadores em Brasília, no qual a formação profissional aparece como tema fundamenta| ${ }^{\mid b}$. E, embora o curso de São Paulo tivesse sido um sucesso, talvez fosse pouco provável que voltasse a acontecer naquela cidade. 
curso realizou-se no final de 1976, em Recife. Pernambuco era um estado-chave para o PCH e para o patrimônio. Desde o princípio, a Delegacia Regional do Ministério do Planejamento em Recife assumiu papéis de coordenação das atividades. No que se refere ao patrimônio, a regional do lphan em Pernambuco estava, assim como a de São Paulo, dentre as quatro primeiras fundadas. Seu diretor era Ayrton de Carvalho, figura respeitada no meio, com atuação muito significativa. Contudo, ele terá um papel bem diferente daquele assumido por Saia em 1974, ainda que atuando como um dos docentes ${ }^{62}$. A motivação principal para o curso em Pernambuco adveio do Programa de Cidades Históricas e do lugar de destaque que o curso vai assumir no seu contexto. $\bigcirc$ Iphan continuará um parceiro fundamental, mas não mais a partir da regionais, como foi o caso de São Paulo, e sim da área central e na sua articulação com a coordenação do PCH.

As primeiras documentações sobre o curso de 1976 datam de dezembro de 1975 e revelam que a intenção inicial era a de se realizar dois cursos simultâneos, na Bahia e em Pernambuco ${ }^{63}$. Por razões não evidenciadas, o curso viabiliza-se somente em Recife, a partir de convênio entre a Secretaria de Planejamento da Presidência da República, a Universidade Federal de Pernambuco e o Iphan. Sai o Ministério da Educação e Cultura, cujos interesses no ensino superior e na pós-graduação motivaram o curso de 1974, e entram as políticas de planejamento do governo federal. $\bigcirc$ programa do curso havia sido aprovado de antemão pelo Iphan e pela Secretaria executiva do $\mathrm{PCH}$. $\bigcirc$ Iphan serviria de supervisor do curso e prestaria à UFPE a assistência técnica necessária ao seu funcionamento ${ }^{64}$. Os objetivos do curso eram:

1) Proporcionar aos participantes uma visão geral do acervo cultural do País, ressaltando a necessidade de sua valorização pelo papel que desempenha na criação de uma identidade cultural.

2) Aprofundar o conhecimento dos participantes sobre as realizações urbanísticas e arquitetônicas brasileiras, a partir do início da colonização.

3) Desenvolver conhecimento sobre materiais, técnicas e sistemas construtivos da arquitetura tradicional, bem como sobre técnicas de conservação.

4) Promover o aprendizado das técnicas de restauração, tanto do ponto de vista teórico como prático, bem como das pesquisas de apoio, indispensáveis à elaboração de projetos consistentes de restauração ${ }^{65}$.

A verba para sua realização veio diretamente da Presidência da República, na ordem de R\$1.032.000,00 cruzeiros, equivalentes a 80\% do montante necessário. A UFPE executaria os recursos e se encarregaria dos $20 \%$ faltantes. $\bigcirc$ coordenador foi o professor do curso de arquitetura da universidade, o arquiteto Armando de Holanda Cavalcanti. $\bigcirc$ curso de formação de arquitetos interessava ao Programa da Cidades Históricas na medida em que serviria às intenções de trazer para o centro das discussões os estados executores das políticas de preservação. Os alunos seriam indicados pelos estados envolvidos no programa, os quais deveriam vir para Recife com estudos de caso de bens culturais de interesse
62. Telegrama de Ayrton de Carvalho a Renato Soeiro informando d a impossibilidade de representar o Iphan na comissão para indicar alterações no Curso de Restauração em 9 ago. 1976. Arquivo Central do Iphan, no Rio de Janeiro.

63. MEC/Iphan, Projeto de Cooperação Técnica Internacional, 6 set. 2015, p.2. Arquivo Central do Iphan, no Rio de Janeiro.

64. Convênio publicado no Diário Oficial da União em 07 jul. 1976.

65. Cf. parecer da Secretaria Executiva do Programa sobre o Projeto do Curso de Especialização em Restauração e Conservação de Monumentos e Conjuntos Históricos para Arquitetos, p. 2. Arquivo Central do Iphan, no Rio de Janeiro. 
66. Idem, p. 3.

67. Convênio Seplan/Iphan/ UFPE, Curso de Especialização em Restauração e Conservação de Monumentos e Conjuntos Históricos, Informe aos candidatos. Arquivo Central do Iphan, no Rio de Janeiro.

68. Ver Maria Sabina Uribarren (2015, p. 162166)

69. Cf. Jornal do Brasil, 10 dez. 1975 (grifos meus). Arquivo Central do Iphan, no Rio de Janeiro. à resłauração já previamente selecionados e com documentação básica (levantamento arquitetônico e fotográfico, informações históricas e referências bibliográficas). Ao longo dos 45 dias de curso, além das aulas teóricas, os alunos desenvolveriam um projeto de restauração para os edifícios, retornando para casa com algo pronto para ser executado. As edificações seriam selecionadas de acordo com os Programas Plurianuais de Valorização do Patrimônio Histórico e Artísitico dos Estados do Nordeste, para posterior implementação pelo $\mathrm{PCH}^{\text {tob }}$. De uma vez só, se resolveriam os projetos de arquitetura e o necessário envolvimento dos estados. As 30 vagas do curso foram massivamente ocupadas por arquitetos de Norte e Nordeste, embora contando com alguns poucos representantes do Sudeste, conforme indicação do Iphan. Após serem indicados para o curso, todos passaram por uma prova que se realizou em Salvador (para candidatos de Sergipe e Bahia), Recife (para candidatos do Rio Grande do Norte, Paraíba, Pernambuco e Alagoas) e em Fortaleza (para candidatos do Maranhão, Piauí e Ceará) versando sobre arquitetura tradicional e planejamento arquitetônico. Os temas a serem estudados eram, suscintamente: materiais e técnicas construtivas da arquitetura colonial brasileira, arquitetura religiosa e jesútica, organização urbana colonial, arquitetura civil e religiosa dos séculos XVI ao XVIII e o domínio holandês no Brasil. Noções de metodologia de projeto e planejamento eram também requeridas dos candidatos ${ }^{67}$.

Como de resto nos direcionamentos do $\mathrm{PCH}$, as estratégias de planejamento e gestão cumpriram papel fundamental. Buscou-se articular ao máximo esforços para viabilizar o programa. Assim como os alunos seriam envolvidos nas obras, os professores serão selecionados a partir dos propósitos do $\mathrm{PCH}$. A Unesco, já uma velha parceria do Patrimônio, será mais uma vez acionada. Como mostrou Sabina Uribarren, desde os anos 1960 que o investimento na formação de pessoal técnico especializado era objeto de atenção de organismos internacionais, como ICOM e a UNESCO, em particular no continente americano. Os contatos começaram primeiro no México para a realização de diversos cursos de especialização em restauração de bens culturais que tiveram alcance continental. Em 1967, foi criado o Centro Regional Latino-americano de Estudios para la Conservación de Bienes Culturales (CERLACOR) que, na década de 1970, ajudou a criar outros centros em países das Américas. Havia um ambiente de cooperação estabelecido entre os diversos países, do qual o Brasil fazia parte e com fortes contatos com a Unesco68.

Ainda em 1975, o consultor da Unesco, Hector Arena, veio ao Brasil para tratar do tema da formação de quadros técnicos e projetos na América Latina. O Jornal do Brasil anunciou em nota de 10 de dezembro de 1975 a sua vinda, com certo alarmismo: "Está no Brasil o Assistente de Preservação do Patrimônio Histórico e Artístico da UNESCO, Sr. Hector Arena. Vai ficar horrorizado"69.

Na sequência da vinda de Hector Arena, organizou-se o "Projeto de Cooperação Técnica Internacional" entre Iphan e Unesco para formação de pessoal técnico especializado em restauração de monumentos e sítios de valor cultural. No escopo do acordo de cooperação estava, além da vinda de consultores 
internacionais selecionados com a ajuda da Unesco para o curso de extensão universitária, a realização de um seminário sobre o deslizamento de encostas em Olinda/PE e uma viagem de técnicos do Iphan para intercâmbio de experiências com o Programa Regional do Peru (Plano COPESCO), onde estavam em curso extensos trabalhos arqueológicos e de restauração de monumentos na área de Cusco, inclusive com cursos de formação ${ }^{70}$.

No que se referia ao curso, o Projeto de Cooperação Técnica discriminava os interesse do Iphan, solicitando especialistas nas áreas lacunares. Aproveitava-se a vinda de especialistas para o curso para que os técnicos do Iphan pudessem também se favorecer de novos conhecimentos e de ajuda em casos específicos. Para 1976, o pedido era de quatro especialistas nas seguintes áreas:

\footnotetext{
- um especialista em iluminação de monumentos e de sítios históricos;

- um especialista em projetos de interior e ambientação interna, e em agenciamentos de casas históricas e de museus;

- um técnico sul-americano, especialista em obras de preservação de bens culturais /arq. Victor Pimentel, do Peru, ou Graziano Gasparini, da Venezuela):

- um prolongamento por período de uns quinze dias da permanência do arquiteto Viana de Lima, que deverá vir ao Brasil em missão da Unesco, para possibilitar sua participação no curso¹.
}

Os especialistas que não conheciam o Brasil viajariam pelo país por 15 dias além do período das aulas para conhecer o "acervo brasileiro". A Unesco ajudaria na localização dos possíveis docentes e cobriria as despesas com diárias e passagens. Após alguns debates, chegou-se na sugestão de nomes: Viana de Lima (português), Yves Raux-Deledicque (francês radicado em Buenos Aires, especialista em luminotécnica), Raul Pastrana (arquiteturas e ambientação) e Victor Pimentel (pervano, especialista em restauração de monumentos). A articulação com a América Latina se fortalecia, tendo também em vista que a Unesco financiaria a ida de oito especialistas brasileiros para o Peru no mesmo período. Alguns nomes já eram conhecidos do Iphan, como Viana de Lima, consultor da Unesco para o Plano Diretor de Ouro Preto e professor no Curso de 1974. Os latino-americanos também eram "amigos do patrimônio", como Victor Pimentel, do Peru. Raux-Deledicque não havia sido mencionado em momentos anteriores e ganhou a vaga de professor por sua especialidade em iluminação de monumentos, um tema que ganhou interesse dos brasileiros. A temática da ambientação de monumentos e seu reaproveitamento era fundamental no âmbito do PCH. O aproveitamento turístico dos bens culturais, visando sua viabilidade econômica era desafio novo para a instituição, e implicava em dar usos diferentes dos originais para os bens culturais. Embora os técnicos do Iphan estivessem habituados à prática da restauração, os novos usos em preexistências eram relativa novidade para os arquitetos do patrimônio.

$\bigcirc$ primeiro nome aventado para as aulas do curso foi o da arquiteta italiana Franca Helg, que acabou vindo para o curso de 1978. Em substituição à arquiteta, a Unesco sugeriu o nome de Raul Pastrana, que não foi prontamente
70. MEC/Iphan, Projeto de Cooperação Técnica Internacional, s/d. Arquivo Central do Iphan, no Rio de Janeiro.

71. Idem. 
72. Carta de Augusto da Silva Telles a Hector Arena, 1 jun. 1976. Arquivo Central do Iphan, no Rio de Janeiro.

73. Depoimento de Luiz Eduardo Pinheiro à autora em 19 out. 2015.

74. Sobre as viagens dos arquitetos, ver João Clark de Abreu Sodré (2010).

75. Relatório de atividades da coordenação do Curso de Especialização em Restauração e Conservação de Monumentos e Conjuntos Históricos, durante os meses de setembro a outubro de 1976. Arquivo Central do Iphan, no Rio de Janeiro.

76. Foram estes os alunos inscritos: Luiz Eduardo Pinheiro Silva (Maranhão), João Alberto Monteiro (Piauí), Francisco Augusto S. Veloso (Ceará), Margarida Andrade (Ceará), Maria Amável Sobrinha (Ceará), Vera Mamede Accioly (Ceará), Claudino Alves da Nóbrega (Rio Grande do Norte), Alberto José de Sousa (Paraíba), Cremilda A 1 b u q u e $r$ q u e (Pernambuco), Elias José Gomes (Pernambuco), Luciano Pinheiro (Pernambuco), Maria de Fátima Oliveira (Pernambuco), Marta Alves (Pernambuco), Silvia Katz (Pernambuco), Sônia Calheiros (Pernambuco), Tania Cruz de Góis (Pernambuco), Geisa Ramalho (Alagoas), José Wallington Costa (Sergipe), Marta Menezes Silva (Sergipe), Alberto João da Cruz (Bahia), Eduardo Lucas (Bahia), José Arli Sobrinho (Bahia), Nadir Franco Lima (Bahia), Odete Dourado (Bahia), Paulo Roberto Nunes (Bahia), Alexandre Freital Hissa (Distrito Federal), Marlo Figueredo da Costa (Rio de Janeiro) e Helena Saia (São Paulo).

77. Primeira aula do Professor Fernando Leal no aceito, sob a alegação de que a descrição de seu currículo era imprecisa. Augusto da Silva Telles, consultor técnico do Curso de 1976 e responsável pelas negociações com a Unesco, explicita que "o que desejávamos, realmente, era alguém conhecedor de arranjo e composição de interiores em monumentos históricos, pois que constitui problema difícil, de pequena ou nenhuma experiência por aqui"72. É enviada pela Unesco a informação de que Raul Pastrana, além de suas atividades como professor da Faculdade de Arquitetura e Urbanismo de Paris, realizou intervenções na Casa Argentina de Paris, na Câmara de Comércio e no Centro de Formação de Bordeux, França. Seu nome acabou aceito e o professor participou das edições de 1976 e 1978 do curso.

Os especialistas ficaram com os temas que o Iphan definiu como suas fragilidades ou deficiências e que o corpo técnico não poderia suprir. De resto, as aulas práticas e teóricas de restauração, projetos de restauração, história da arquitetura, estudos dos problemas da cultura brasileira e visitas de campo eram ministradas pelo corpo técnico do instituto. Alcides da Rocha Miranda, Augusto da Silva Telles, Ayrton de Carvalho, Fernando Leal, Edson Motta, José de Souza Reis compuseram o corpo docente oriundo do Iphan. Além desses, o Mestre Ferrão de Pernambuco participou do curso e conquistou a todos com seus conhecimentos de restauração ${ }^{73}$. De Pernambuco ainda, participaram como docentes, entre outros, Geraldo Gomes, Hélvio Polito, Armando de Holanda Calvalcanti, Roberto Lacerda e José Luiz da Mota Menezes. Da Bahia, compuseram o corpo docente Paulo Ormindo de Azevedo, Diógenes Rebouças e Américo Simas, e de São Paulo vieram os professores Ulpiano Bezerra de Meneses e Nestor Goulart Reis Filho para ministrar as disciplinas que haviam dado em 1974. Cyro Lira, da Universidade Federal do Paraná e parceiro do Iphan, deu aulas no Atelier de Restauração. Observe-se que a estrutura do curso foi similar à de São Paulo, com módulos teóricos, práticos e viagens. Essas eram parte essencial da formação, uma prática comum nas faculdades de arquitetura do Brasil74. Num momento em que o turismo encontrava espaço no discurso patrimonial, poucos eram aqueles que conheciam os sítios de interesse à restauração, para além da "gente do patrimônio". A viagem ao Norte e ao Nordeste, feita de 10 a 23 de outubro, seguiu o roteiro (saindo e retornando por Recife): Goiana, João Pessoa, Cabedelo e Guia, Natal, Mossoró, Aracati, Aquiráz, Fortaleza, Sobral, Tianguá, Sete Cidades, São Luiz, Alcântara, Teresina e Oeiras $^{75}$.

A diferença substantiva desse para o primeiro curso era a de que o último foi realizado em menos tempo, 45 dias, em prejuízo dos conteúdos da formação histórica nacional. $\bigcirc$ peso maior foi dado às aulas teóricas e práticas de restauração. $\bigcirc$ resultado final foram 29 projetos de restauração, pois dos 30 alunos inscritos, o arquiteto que representaria a Divisão de Patrimônio Histórico da Guanabara desistiu76. As edificações selecionadas para projeto no curso representavam a política de patrimônio delineada pelo lphan no final dos anos 1930: sobrados, casas térreas, igrejas, conventos, casas de câmara de cadeia, fortes, solares e um conjunto urbano de Laranjeiras. Fernando Leal77, em aula do 
Curso de 1974, afirmara que o desafio deixado pela geração fundadora do Iphan à geração atual (de alunos do curso) não era pequeno. Era o de preservar os bens culturais que haviam legado às gerações seguintes. A seleção estava feita, cumpria agora garantir sua permanência conforme dever legal. Esste talvez fosse o maior propósito dos cursos de formação.

Os ateliers de projeto foram novidade fundamental, pois os alunos projetavam no período da tarde, sempre com a interlocução dos professores. Segundo Luiz Eduardo Pinheiro ${ }^{78}$, aluno do curso formado no Rio de Janeiro, mas radicado no Maranhão e representante da Fundação de Cultura do Estado, os debates foram acalorados e ricos. $\bigcirc$ ambiente era de franca abertura à discussão e aos questionamentos. Muito se argumentou sobre restauração, projeto de arquitetura e caminhos da preservação na especialização. Assim como em 1974, as visitas técnicas às obras fomentaram estranhamentos de toda ordem. Como conciliar as práticas do Iphan com as teorias de aula sobre restauração? Como fazer projetos consistentes, úteis e, ao mesmo tempo, coerentes? Foram perguntas colocadas mais uma vez diante das experiências como a restauração da Sé de Olinda e as aulas de Augusto da Silva Telles sobre Teoria da Conservação. Se em 1974 o arquiteto do Iphan já discutia a Carta de Veneza, em 1976, a sua disciplina "Teoria da Restauração" ampliou conceitos, como se pode verificar pela ementa ${ }^{79}$. Discutiram-se conceitos de monumentos e bens culturais, a integração com o entorno e o testemunho histórico social que representavam e, também, a função social no monumento e do conjunto histórico para a comunidade. $\bigcirc$ professor apresentou a Carta de Amsterdã, a Convenção Europeia do Patrimônio, trouxe o debate do patrimônio natural, da gestão de sítios de interesse histórico e finalizou com a preservação do patrimônio histórico como área interdisciplinar. Ou seja, um leque amplo de questões colocadas para o patrimônio cultural na década de 1970, nas quais - Iphan estava imiscuído.

A crítica à atuação institucional do Iphan e ao mesmo tempo o louvor às suas práticas andaram juntas no Curso de Especialização de 1976. Note-se que tanto o PCH (na sua concepção, gestão e forma de atuação) como a pósgraduação em patrimônio eram novidades grandes na história da preservação no Brasil. O Iphan moveu-se em conjunto com as políticas do governo federal e firmouse como parceiro fundamental naquilo que tinha de mais simbólico: os seus saberes e fazeres. Ao formar profissionais de fora de quadros institucionais, associando-se às universidades, o lphan buscava o lugar de gestor de competências e interlocutor, legitimando sua existência e permanência. Os dois primeiros cursos, embora acompanhados de perto pelo Iphan, haviam sido deslocamentos grandes do ponto de vista intelectual e geográfico: São Paulo e Pernambuco estavam longe da Minas Gerais setecentista. Os professores nacionais e estrangeiros, bem como os alunos oriundos de lugares diversos, trouxeram novos ares ao campo, mesmo que a partir dele mesmo e reiterando alguns de seus valores. A ambiguidade da crítica ao lado da exaltação foi uma constante.
Curso de Restauração e

Conservação d e

Monumentos e Conjuntos Urbanos, 5 set.1974. Arquivo do Iphan, em São Paulo.

78. Depoimento de Luiz Eduardo Pinheiro à autora em 19.10.2015.

79. Ementa da disciplina "Teoria da Conservação" do Prof. Augusto da Silva Telles para o Curso de Restauração e Conservação de Monumentos e Conjuntos Urbanos de 1976, Convênio SEPLAN/ IPHAN/UFPE. Arquivo Central do Iphan, no Rio de Janeiro. 
80. Ver Márcia Chuva (2009).

81. Valho-me aqui da cronologia que Daniel Aarão Reis estabelece para o período da ditadura civilmilitar de 1964 a 1979. A década de 1980 até a Constituição Cidadã e as eleições democráticas de 1989 seria o lento período de redemocratização. Ver Daniel Aarão Reis (2014b, p.23-29).

82. Ver Sandra Correa (2012).

83. Relatório final do Convênio SEPLAN-PR/ UFMG/FUNDEP, Curso de Especialização em Restauração e Conservação de Monumentos e Conjuntos Históricos, Escola de Arquitetura da UFMG, 1978. Biblioteca da Escola de Arquitetura da UFMG.

84. Curso de Especialização em Restauração e Conservação de Monumentos e Conjuntos Históricos, Proposição, 1a versão. Arquivo Central do Iphan, no Rio de Janeiro.

85. Convênio firmado em 29 dez. 1977 entre a Secretaria de Planejamento da República, a UFMG, o Iphan e a Fundação de Desenvolvimento da Pesquisa para o Curso de Especialização em Restauração e Conservação de Monumentos e Conjuntos Históricos para Arquitetos. Arquivo Central do Iphan, no Rio de Janeiro.
De volta a Minas Gerais: o III Curso de Restauração, 1978

O patrimônio mineiro e barroco que havia moldado e dado concretude à nação do período estadonovista ${ }^{80}$ se apresentou novamente potente no Brasil do final do período militar ${ }^{81}$. Depois dos muitos investimentos no Nordeste e no Norte, - Programa das Cidades Históricas era pressionado a fazer investimentos no Sudeste e no Sul do país, o que só ocorreria efetivamente a partir de 1979, quando apesar de continuar chamado $\mathrm{PCH}$, o programa muda significativamente sua forma de gestão. Deixa de ser coordenado pelo Ministério do Planejamento e passa a ser atribuição do Iphan em conjunto com a recém-criada Fundação Prómemória. Uma das suas singularidades, a de deslocar o patrimônio do escopo específico do Iphan para tornar-se política governamental, articulando vários ministérios e órgãos públicos, voltava a ser assunto do "Patrimônio"82. Outra diferença importante era de que, desde 1977, O PCH, atendendo a pressões, incluiu no seu escopo de atuação os Estados de Minas Gerais, Rio de Janeiro e Espírito Santo, locais que contavam com significativo número de bens tombados ${ }^{83}$.

Diante dessas mudanças, o Sudeste voltou ao centro das atenções e, logo em 1977, a Escola de Arquitetura da Universidade Federal de Minas Gerais organizou uma proposta de curso sob a coordenação da Professora Suzy de Mello, docente de História da Arquitetura no Curso da UFMG, com especialização na Itália, estudiosa do barroco mineiro e da arquitetura rural. Embora estudiosa de temas afins ao Iphan, a professora não era vinculada ao instituto. Como em Recife, a coordenação ficava com a universidade, mas todo aparato intelectual e didático estava sob a responsabilidade de Augusto da Silva Telles. A justificava para o curso de Belo Horizonte foi a de sempre: aumentariam as obras de restauração na região e os profissionais seriam necessários, diante da propalada escassez. $\bigcirc$ curso ajudaria no fomento a atividades turísticas em áreas históricas em "desagregação ou empobrecimento" e nas que já tivessem atividades turísticas consolidadas ou em vistas de consolidação ${ }^{84}$. Assim como em Recife, o curso estava vinculado às políticas de patrimônio em andamento em nível federal, realizadas no âmbito do $\mathrm{PCH}$. E, também como das outras vezes, foi firmado convênio entre o Iphan, a UFMG, a Secretaria de Planejamento da Presidência da República e a Fundação de Desenvolvimento da Pesquisa, no qual estabeleciam-se os parâmetros e as propostas de sua organização. A Presidência da República repassou R $\$$ 2. 190.177,00 cruzeiros à UFMG, correspondente a 79,87\% dos custos globais. Em relação ao curso de Recife, o valor aportado pelo governo federal duplicou, o que nos permite inferir a importância estratégica dos Cursos de Especialização em Restauração e Conservação de Monumentos e Conjuntos Históricos para Arquitetos $^{85}$

Embora se quisesse dar um cunho nacional ao curso, a importância de Minas Gerais e de seus monumentos é ressaltada como ímpar, o que também o justificava. Os alunos se beneficiariam de estar próximos a bens de extrema importância para o patrimônio nacional, com acesso fácil a obras de restauração 
em curso, podendo acompanhar suas etapas, um desejo antigo desde o primeiro curso de $1974^{86}$.

A restauração, recuperação ou revalorização dos monumentos de Minas Gerais e da região Sudeste (...), dos mais significativos do país, só poderá ser realizada dentro dos mais altos padrões técnicos, exigindo, portanto, a imediata e indispensável preparação de pessoal especializado $(\ldots)^{87}$.

A estratégia de organização do curso estabelecida pela coordenadora Suzy de Mello em conjunto com Augusto da Silva Telles, consultor técnico do curso, foi dar continuidade às diretrizes de Recife. $\bigcirc$ esquema de curso, as disciplinas, o corpo docente (exceto os internacionais) foram pouco alterados. A diferença mais significativa foi a afirmação da necessidade de se dar uma visão mais nacional dos problemas da arquitetura brasileira, já que o curso de Recife havia se focado excessivamente nos temas regionais. $\bigcirc$ corpo docente deveria ser composto por profissionais de diversos lugares, embora Minas Gerais tenha participado com presença significativa, como as de Afonso Ávila, Francisco Iglésias, Ivo Porto de Menezes e Suzy de Mello. A equipe do Iphan foi basicamente mantida com Silva Telles, Lígia Martins Costa, Roberto Lacerda, Fernando Leal, Cyro Lyra, Edson Motta e José de Souza Reis. $O$ diretor do Iphan, Renato Soeiro, proferiu a conferência de abertura do curso. De outras regiões do Brasil, foram convidados professores que tinham vínculos anteriores com os cursos como Paulo Ormindo de Azevedo, Armando de Holanda, José Luiz Menezes, Hélvio Polito, Nestor Goulart Reis Filho e Roberto Burle Marx (que deu aulas de paisagismo nas versões anteriores) ${ }^{88}$.

A experiência internacional era já uma tradição nos cursos. E, mais uma vez, a Unesco, por meio do convênio com o lphan, providenciou os contatos. A vinda de estrangeiros não tinha apenas o objetivo de ministrar aulas, mas também de prestar assessorias e estabelecer redes no Iphan. Em geral, os professores ficavam cerca de um mês no Brasil, visitando cidades históricas e as regionais do Iphan. Graziano Gasperini, arquiteto venezuelano, que desde 1974 era convidado para dar aulas nos cursos, foi confirmado, mas cancelou sua visita às vésperas da data marcada. As disciplinas Revitalização de Cidades Históricas e Introdução da Arquitetura Contemporânea em Núcleos Históricos, temas que já se haviam anunciado em 1976 nas aulas de Raul Pastrana, foram novidades da edição mineira com o mesmo arquiteto dando continuidade à discussão. $\bigcirc$ francês Jean Bernard Perrin assumiu a disciplina de Revitalização além de realizar um seminário com arquitetos e técnicos interessados e de outros organismos como o Conselho Nacional de Planejamento Urbano e Áreas Metropolitanas - CNPU. A legislação francesa, como a Lei Maulraux, foi discutida no curso juntamente com os desafios da preservação de áreas urbanas. A perspectiva latino-americana, por meio dos contatos que o Iphan já mantinha no continente, também foi continuada. $\bigcirc$ peruano Victor Pimentel, apresentou casos de intervenção em Cusco, mas veio principalmente para dar aulas nos ateliers de projeto. Guillermo Trimmiño Arango, colombiano, deu aulas sobre cadastramento e levantamento de bens culturais no mês de junho de 1976.
86. Idem.

87. Curso de Especialização em Restauração e Conservação d e Monumentos e Conjuntos Históricos, Proposição, 1a versão, p. 2. Arquivo Central do Iphan, no Rio de Janeiro.

88. Curso de Especialização em Restauração e Conservação d e Monumentos e Conjuntos Históricos, Proposição, 1a versão, p. 30-33. Arquivo Central do Iphan, no Rio de Janeiro. 
89. Depoimentos à autora de Lia Motta (9 set. 2015), Dina Lerner (6 set. 2015) e Jurema Arnaut (13 nov. 2015).

90. Frang Helg, Relazione su missione Unesco in Brasile dal 7 luglio al 12 agosto 1978, p. 1-3. Arquivo Central do Iphan, no Rio de Janeiro.

91. Convênio Seplan/Iphan/ UFMG, Informe às entidades interessadas na apresentação de candidaturas (IE/01). Arquivo Noronha Santos.

92. Correspondência de Suzy de Mello com Henrique Oswaldo de Andrade em 19 abr.1978. Ofício $n^{\circ} 125 / 78-$ CO. Arquivo Noronha Santos. Frequentaram o curso os seguintes alunos: Clifford Glenn Dumbar (Minas Gerais), Clóvis Lerner (São Paulo), Dina Lerner (Rio de Janeiro), Fábio Machado (Minas Gerais), Jorge Tinoco (Pernambuco), Jurema Kopke Eis Arnaut (Rio de Janeiro), Lia Motta (Rio de Janeiro), Lívia D’Assumpção (Minas Gerais), Lúcia Oliveira (Paraíba), Luiz Passaglia (São Paulo), Luis Magnani (São Paulo), Luiz Fernando Costa (Minas Gerais), Maria Bittencourt (Minas Gerais), Maria de Fátima Chiança (Minas Gerais), Josefina Maia (Minas Gerais), Marina Machado (Minas Gerais), Marta Melo (Alagoas), Neide Ferreira (Rio de Janeiro), Odair de Almeida (São Paulo), Olavo Silva Filho (Minas Gerais), Rosélia Martins (Minas Gerais), Selma Silva (Minas Gerais). Ver: Relatório final do Convênio SEPLAN-PR/ UFMG/FUNDEP, Curso de Especialização em Restauração e Conservação de Monumentos e Conjuntos Históricos, Escola de Arquitetura da UFMG, 1978.

93. Entrevista de Dina Lerner à autora em set. 2015 .

94. Relatório final do Convênio SEPLAN-PR/ UFMG/FUNDEP, Curso de Especialização em
Mas foi a arquiteta italiana Franca Helg, que já havia sido convidada em 1976, mas não pode comparecer, quem causou mais impacto nos alunos. $\mathrm{Na}$ disciplina "Adequação do uso e ambientação interna dos bens culturais" e também nos ateliers de projeto os seus trabalhos de intervenção e ambientação em bens culturais foram novidade, "apresentando coisas que não se viam por aqui", segundo depoimentos de alguns alunos ${ }^{89}$. Permaneceu no país por cerca de um mês para contatos técnicos e assessorias ao Iphan, visitando Vassouras, Petrópolis, Salvador, Santo Amaro, Cachoeira, Recife, Olinda, Igarassu e João Pessoa ${ }^{90}$.

Quanto ao corpo discente, ele deveria ser composto por profissionais de Minas Gerais (8), Espírito Santo (4), Rio de Janeiro (8), Nordeste (6), além de uma cota para o Iphan (4). Percebe-se que o alvo era a formação de recursos humanos na região Sudeste, já que Centro Oeste, Sul e Norte não aparecem e o Nordeste tem uma parcela menor de participação. Os nomes eram indicados pelas fundações e órgãos de patrimônio, após o que passavam por uma prova de conhecimentos gerais de arquitetura tradicional brasileira e planejamento arquitetônico, nos mesmos moldes da prova anterior, de Recife ${ }^{91}$. Em razão da falta de recursos, o número final foi reduzido para 22 alunos, mormente do Sudeste. Todos, exceto os residentes em Belo Horizonte, tinham bolsas para custos com acomodação e alimentação ${ }^{92}$.

Para os alunos do curso, as visitas de campo eram parte essencial da proposta, e, como em São Paulo e Pernambuco, eles percorreram muitas regiões do Brasil. As visitas aos canteiros foram em cidades próximas a Belo Horizonte: Caeté, Santa Bárbara, Catas Altas, Sabará, Ouro Preto e Mariana. Material informativo das obras visitas preparado pelo arquiteto Roberto Lacerda, do Iphan/ MG, era distribuído aos alunos. Em junho de 1976, começaram as viagens mais distantes por Minas (Congonhas do Campo, Tiradentes, São João del Rei), de onde seguiram para o Rio de Janeiro (visitando Mosteiro de São Bento, Valongo, Praça XV, outeiro da Glória, Convento de São Antônio, Casa de Grandjean de Montigny - ressentiram-se de não ter ido ao Palácio Gustavo Capanema), Niterói, Vassouras, Bananal, chegando a São Paulo (Sítio do Padre Inácio, São Miguel Paulista, FAU USP, Casa Modernista, Casa Bandeiristas, casas art nouveau), São Sebastião, Paraty, Mambucaba, finalizando em Angra dos Reis. A segunda viagem ocorreu entre 15 e 25 de agosto de 1976, indo para Espírito Santo, Bahia e Norte de Minas. Durante as viagens, os alunos faziam croquis e fotografias dos obras visitadas e registravam as soluções de restauração ${ }^{93}$.

$\bigcirc$ curso começou em fins de março de 1978 e foi até setembro do mesmo ano, com cerca de seis meses de duração, e um breve recesso entre a primeira e a segunda parte. Os 45 dias de aula em Recife foram considerados insuficientes para o conteúdo teórico e o desenvolvimento dos projetos de restauração. A carga horária de atelier foi aumentada para que os alunos pudessem elaborar as propostas e desenvolvê-las como produto final para ser utilizado. A ênfase era na prática de projeto de restauração, com exercícios de desenho e levantamento nas viagens e projetos na prancheta $^{94}$. Segundo depoimento de 
alunos como Dina Lerner e Luiz Eduardo Pinheiro, alunos do curso de 1978 e 1976 respectivamente, a margem de discussões e debates foi muito menor do que em 1976. Basta dizer que atestados de bons antecedentes foram exigidos de alguns participantes 95 . Em São Paulo e em Pernambuco, segundo depoimentos, os debates sobre conceitos e práticas foram grandes.

Em Belo Horizonte, talvez o compromisso com a elaboração de projetos de restauração que pudessem ser executados tenha se sobreposto aos debates. A impressão do arquiteto peruano Cesar Roberto Samañez Argumedo sobre o curso em Belo Horizonte, foi nesse sentido, causando algum ruído junto à coordenação ${ }^{96}$. Juntamente com o coordenador da Seção de Operações e Formação da Unesco, Hector Arena (responsável pelo convênio com o Iphan para o curso), Samañez ficou poucos dias no Brasil, com o propósito de avaliar os cursos de restauração de monumentos com a participação da Unesco na América Latina. Docente no curso em Cusco no contexto do Plano Copesco, o professor Roberto Samañez veio em missão ao Brasil, com breve passagem por Belo Horizonte. Suas impressões foram duras. Observou que havia pouca prática de restauração, já que os alunos tinham muitas aulas teóricas e contato com as obras somente nas viagens de campo. Estranhou a falta de homogeneidade nos casos escolhidos, observação também feita por Franca Helg, e foi claro ao afirmar que deveria ser dada maior liberdade para que os alunos pudessem encontrar alternativas e soluções aos projetos: "Considero que en el nível de formación debe inducirse mayor libertad para que el restaurador que está formando pueda investigar y talvez encontrar otras alternativas y soluciones, siempre en el marco estabelecido por las normas y criterios internacionais" 17 .

Os projetos finais com os quais o peruano teve contato foram avaliados por uma banca final composta por Augusto da Silva Telles, Fernando Leal, Roberto Lacerda, Ivo Porto de Menezes e Suzy de Mello. Os bens culturais foram selecionados antes da inscrição no curso, com o aval do lphan, constando do escopo do Plano Plurianual dos Estados e desde que de interesse prioritário. Tinham, em sua maioria, os perfis colonial e barroco e excepcional. Sobrados e casas térreas, fazendas e sítios, conventos, igrejas e capelas coloniais, casas bandeiristas. Poucos foram os conjuntos urbanos, como o Conjunto Arquitetônico do Valongo, no Rio de Janeiro, feito por Jurema Arnaut, e a Vila Maria Zélia em São Paulo, por Luis Magnani. Alguns projetos propunham novas funções, como Convento de São Bernardino de Sena, em Angra dos Reis, por Lia Motta, e a Casa Bandeirista, no Tatuapé, de Luiz Passaglia, como museu e centro cultural ${ }^{98}$. As obras e os programas eram definições prévias do lphan, como foi no caso de Dina Lerner, então arquiteta da Fundrem (Fundação para o Desenvolvimento da Região Metropolitana do Rio de Janeiro), que foi responsabilizada pelo projeto para a lgreja de Nossa Senhora do Pilar em Duque de Caxias/Rj ${ }^{99}$.

representante do Iphan de São Paulo, Odair Carlos de Almeida, apresentou um Anteprojeto de Restauração da Fazenda Nossa Senhora da Conceição, em Paraibuna/SP que permite antever a qualidade possível dos
Restauração e Conservação de Monumentos e Conjuntos Históricos, Escola de Arquitetura da UFMG, 1978.

95. Declaração de Augusto da Silva Telles para Arquiteta Dina Lerner atestando sua boa "conduta cívica e moral". 26.6.1978. Arquivo Central do Iphan, no Rio de Janeiro.

96. Relatório final do Convênio SEPLAN-PR/ UFMG/FUNDEP, Curso de Es pecialização em Restauração e Conservação de Monumentos e Conjuntos Históricos, Escola de Arquitetura da UFMG, 1978.

97. Informe del Consultor/ Unesco 597496 Arq. Cesar Roberto Samañez Agumedo, set.1976, p. 5. Arquivo Central do Iphan, no Rio de Janeiro.

98. Ofício $\mathrm{n}^{\circ} 171 / 79-\mathrm{CO}$ de Suzy de Mello a Henrique Oswaldo encaminhando a relação de projetos finais do Curso. 7 mar. 1979. Arquivo Central do Iphan, no Rio de Janeiro.

99. Em depoimento, a arquiteta Dina Lerner contou que dado seu trabalho na Fundrem, sua escolha seria por conjunto urbano do fundo da Baía de Guanabara objeto de suas atividades. Entrevista à autora em 6 set. 2015. 
100. Ofício $\mathrm{n}^{\circ} 055 / 79-\mathrm{CO}$ de Suzy de Mello a Henrique Oswaldo encaminhando o resultado final obtido pelos arquitetos matriculados. 31 jan. 1979. Arquivo Central do Iphan, no Rio de Janeiro.

101. Odair José de Souza. Anteprojeto de Restauração da Fazenda Nossa Senhora da Conceição, em Paraibuna, 1978. Arquivo do Iphan/SP. produtos dos cursos. Na média final do curso (frequência, relatórios, anteprojeto e defesa oral), o aluno passou com nota 9,55 umas das mais altas de sua turma ${ }^{100}$. Um levantamento minucioso da edificação, acompanhado de estudos históricos sobre a tipologia das fazendas paulistas, análises comparativas, levantamento fotográfico, hipóteses formais e documentação histórica, era finalizado por um projeto de restauração. $\bigcirc$ caso era bastante complicado, estendendo-se até os dias atuais, pois a edificação acabou por arruinar-se. Já na ocasião, o proprietário não estava interessado na recuperação, a não ser que financiada pelo Iphan e destinada a seu usufruto.

Para contornar o problema, o arquiteto resolveu adotar "um caminho mais aberto" e analisar as várias alternativas de destinação. A partir do estudo tipológico da edificação, passou a especular sobre as destinações que melhor se adequavam à fazenda, diante de características como iluminação, ventilação, entorno, tamanho dos cômodos, etc. Não satisfeito, fez uma enquete com os colegas e professores, listando as sugestões: centro comunitário, instituição de pesquisa sobre a produção leiteira do Vale do Paraíba, casa de cultura, sede de fazenda, casa de campo, clube de campo. A sugestão de Ecomuseu (que havia aparecido nas aulas de Varine-Bohan, em São Paulo, em 1974), foi descartada diante do "elitismo que certamente traria esta atividade". Após tabular todas as vantagens e desvantagens dos usos sugeridos, considerando relação do edifício com a circulação, o grau de intervenção necessária por parte do Iphan, as necessidades socioculturais da região, a localização geográfica e o desenvolvimento do espírito de vizinhança, optou por fazer uma escola rural, estimulado também pelo programa federal em curso ${ }^{101}$. Uma proposta que se desviava das pretensões de uso turístico dos bens culturais almejada pelo PCH. Indício, talvez, dos muitos enfoques, possibilidades e dissensos do patrimônio cultural às vésperas do fim do regime militar.

O curso terminou em 1978 com 22 projetos de restauração finalizados e que foram enviados, no ano seguinte, pela Professora Suzy Mello ao Coordenador do Programa das Cidades Históricas. $O$ resultado foi aclamado como muito bem sucedido e o relatório final da arquiteta detalhou minuciosamente o transcorrer da programação para aproveitamento das próximas edições. Estava posto que o seguinte curso seria em outro local. Em 1981, o curso retornará ao Nordeste, realizando-se na Bahia, voltando a acontecer na mesma cidade em 1984 e onde se instalará em definitivo. A demanda por profissionais e a organização dos cursos de pós-graduação dos anos 1980 garantirá a sua permanência na UFBA até os dias de hoje, na qualidade de mestrado profissional.

Os temas, personagens e práticas que circularam nos cursos de especialização entre 1973 e 1978 nos permitiram compreender o vigor do campo disciplinar da preservação no Brasil nessa década. Eles são parte fundamental das realizações e do campo de atuação, ajudando a problematizar o lugar do Iphan no aparato governamental do governo militar, na qualidade de saber técnico formativo dos órgãos locais de patrimônio em formação e no assessoramento às 
universidades. Teoria da restauração, práticas interdisciplinares, os usos do patrimônio, a história do restauro no Brasil e no mundo, diálogos latino-americanos, práticas internacionais e projetos de restauração foram discutidos à exaustão nesses anos. Dos cursos participaram arquitetos que se engajaram no campo do patrimônio cultural nas décadas seguintes em todo o país. Professores, técnicos em níveis municipal, estadual e federal que frequentaram as edições do curso, tiveram nos anos da reabertura política muito campo de atuação, esperança e crítica.

O Programa das Cidades Históricas havia se iniciado em 1973 com a motivação de dar uso aos monumentos nacionais, viabilizando-os como produtos turísticos. As inúmeras dificuldades, questionamentos e entraves que o programa gerou aparecem nos debates dos cursos de especialização dos anos 1970. Mas, os três cursos aqui analisados são também um de seus produtos mais ricos. $O$ financiamento dos programas de ensino pelo Governo do Estado de São Paulo e pela Presidência da República nos mostra o lugar do patrimônio "histórico e artístico" na construção de argumentos de nacionalidade e identidade nesse período. Permitem-nos conhecer com propriedade personagens, agentes, projetos e realizações do campo que ao mesmo em que "transbordou" do Iphan, mantevese muitas vezes no seu próprio "pires". Mesmo não sendo um agente financiador, propositor ou mesmo executor, o Iphan e seus técnicos foram o "intelecto" dos projetos educacionais. Ao manejarem com questionamentos, críticas, novas legislações e cânones dentro e fora de seus limites, os arquitetos da memória, para usar a expressão de Márcia Chuva, reelaboraram e escreveram suas próprias memórias no âmbito do ensino, fazendo-as legado, história e patrimônio das gerações futuras. 


\section{REFERÊNCIAS}

\section{DOCUMENTAÇÃO PRIMÁRIA}

Arquivo Central do Iphan, Brasília

Prova escrita aplicada no IV Curso de especialização em conservação e restauração de monumentos e conjuntos históricos. Arquivo Central do Iphan, em Brasília

Arquivo Central do Iphan, Rio de Janeiro

Carta de Augusto da Silva Telles a Hector Arena, $1^{\circ}$ jun. 1976.

Convênio Secretaria de Planejamento da República, a UFMG, o Iphan e a Fundação de Desenvolvimento da Pesquisa para o Curso de Especialização em Restauração e Conservação de Monumentos e Conjuntos Históricos para Arquitetos, 29 dez. 1977.

Convênio Seplan/Iphan/UFMG, Informe às entidades interessadas na apresentação de candidaturas (IE/01).

Convênio Seplan/Iphan/UFPE, Curso de Especialização em Restauração e Conservação de Monumentos e Conjuntos Históricos, Informe aos candidatos.

Curso de Especialização em Restauração e Conservação de Monumentos e Conjuntos Históricos, Proposição, 1a versão.

Declaração de Augusto da Silva Telles para Arquiteta Dina Lerner atestando sua boa "conduta cívica e moral". 26.6.1978.

Ementa da disciplina "Teoria da Conservação" do Prof. Augusto da Silva Telles para o Curso de Restauração e Conservação de Monumentos e Conjuntos Urbanos de 1976, Convênio SEPLAN/IPHAN/UFPE.

Frang Helg. Relazione su missione Unesco in Brasile dal 7 luglio al 12 agosto 1978.

Informe del Consultor/Unesco 597496 Arq. Cesar Roberto Samañez Agumedo, set.1976.

Jornal do Brasil, Rio de Janeiro, 10 dez. 1975.

MEC/Iphan, Projeto de Cooperação Técnica Internacional, s/d.

Ofício $\mathrm{n}^{\circ}$ 171/79-CO de Suzy de Mello a Henrique Oswaldo encaminhando a relação de projetos finais do Curso. 7 mar.1979.

Ofício n ${ }^{\circ}$ 555/79-CO de Suzy de Mello a Henrique Oswaldo encaminhando o resultado final obtido pelos arquitetos matriculados. 31 jan.1979.

Parecer da Secretaria Executiva do Programa sobre o Projeto do Curso de Especialização em Restauração e Conservação de Monumentos e Conjuntos Históricos para Arquitetos. 
Relatório de atividades da coordenação do Curso de Especialização em Restauração e Conservação de Monumentos e Conjuntos Históricos, durante os meses de setembro a outubro de 1976.

Telegrama de Ayrton de Carvalho a Renato Soeiro informando da impossibilidade de representar o Iphan na comissão para indicar alterações no Curso de Restauração em 9 ago. 1976.

Arquivo da Superintendência do Iphan, São Paulo

Anteprojeto de Restauração da Fazenda Nossa Senhora da Conceição, em Paraibuna. Odair José de Souza, 1978.

Curso de Restauração e Conservação de Monumentos e Conjuntos Históricos, 1974.

Convênio que entre si fazem do Ministério da Educação e Cultura e o Governo do Estado de São Paulo, através de sua Secretaria de Cultura Esportes e Turismo.

Currículo de Renato Soeiro no Programa do Curso de Restauração e Conservação de Monumentos e Conjuntos Históricos, s/d.

Documento de aprovação do convênio entre MEC, Secretaria de Estado de Cultura e USP para realização de curso de restauração para arquitetos, Conselho Universitário da USP, 19.5.1970.

Memorando de Renato Soeiro ao Ministro da Educação e Cultura, 21 jul.1971.

Ofício de Jarbas Passarinho ao Governador do Estado de São Paulo, Dr. Alceu Sodré em 02 abr. 1971.

Ofício de Nestor Goulart Reis Filho a Luiz Saia, 28 abr.1969.

Parecer de Lucio Costa sobre o Curso de Restauração e Conservação.

Parecer do conselheiro Luiz Saia ao Processo $n^{\circ}$ 6927/70, da Secretaria de Estado de Cultura, Esportes e Turismo, 13 mai.1970.

Parecer do conselheiro Luiz Saia ao Processo n ${ }^{\circ}$ 6927/70, da Secretaria de Estado de Cultura, Esportes e Turismo, 13 mai.1970.

Primeira aula do Professor Fernando Leal no Curso de Restauração e Conservação de Monumentos e Conjuntos Urbanos, 5 set. 1974.

Programas dos Cursos de Especialização em Restauração e Patrimônio de 1974, 1976, 1978.

Termo de Convênio entre o Ministério da Educação e Cultura e o Governo do Estado de São Paulo, 1973. 
Biblioteca da Escola de Arquitetura da UFMG

Relatório final do Convênio SEPLAN-PR/UFMG/FUNDEP, Curso de Especialização em Restauração e Conservação de Monumentos e Conjuntos Históricos, Escola de Arquitetura da UFMG, 1978.

LEGISLAÇÃO

Decreto-Lei $\mathrm{n}^{\circ}$ 53, de 18 de novembro de 1966 - Fixa princípios e normas de organização para as universidades federais e dá outras providências

Decreto-Lei $n^{\circ} 252$, de 28 de fevereiro de 1967 - Estabelece normas complementares ao Decreto-Lei $\mathrm{n}^{\circ}$ 53, de 18 de novembro de 1966, e dá outras providências.

LIVROS, PERIÓDICOS E TESES

ANDRADE, Carlos Roberto M. de et.al. (coord.). Luís Saia: memória e política. Brasília: Iphan, 2014.

ANDRADE, Paula R. de. O patrimônio da cidade: arquitetura e ambiente urbano nos inventários de São Paulo da década de 1970. Dissertação (Mestrado) - FAU / USP, São Paulo, 2012.

ANDRADE, Rodrigo Melo Franco de. Brasil: monumentos históricos e arqueológicos. Rio de Janeiro: IPHAN/DAF/COPEDOC, 2012.

CALABRE, Lia. Políticas culturais no Brasil: dos anos 1930 ao século XXI. Rio de Janeiro: Editora FGV, 2009.

CHUVA, Márcia R. R. Os arquitetos da memória: sociogênese das práticas de preservação do patrimônio cultural no Brasil (anos 1930-1940). Rio de Janeiro: Editora UFRJ, 2009.

COMPROMISSO de Brasília, documento do I Encontro dos Governadores, Secretários Estaduais da Área Cultural, Prefeitos Municípios Interessados, Presidentes e Representantes de Instituições Culturais, em abril 1970. São Paulo: USP; IAB; DPHAN, s/d.

CONCEIÇÃO, José Luiz da. Curso de Restauração e Conservação de Monumentos e Conjuntos Históricos. Relatórios de Viagem. São Paulo: FAU USP, 1974.

CORREA, Sandra. O Programa de Cidades Históricas (PCH): por uma política integrada de preservação do patrimônio cultural - 1973/1979. Dissertação (Mestrado) - Programa de PósGraduação em Arquitetura e Urbanismo / Universidade de Brasília, Brasília, 2012. 
COSTA, Eduardo. Arquivo, poder, memória: Herman Hugo Graeser e o Arquivo Fotográfico do IPHAN. Tese (Doutorado) - Instituto de Filosofia e Ciências Humanas / Universidade Estadual de Campinas, Campinas, 2015.

FARAH, Ana Paula. Restauro Arquitetônico: a formação do arquiteto-urbanista na Brasil para preservação do patrimônio edificado - o caso das escola do Estado de São Paulo. Tese (Doutorado) - FAU / USP, São Paulo, 2012.

FONSECA, Cecília Londres. O patrimônio em processo: trajetória da política federal de preservação no Brasil. Rio de Janeiro: UFRJ/IPHAN, 1997.

GONÇALVES, Cristiane. Restauração arquitetônica. A experiência do Sphan em São Paulo, 1937-1975. São Paulo: Annablume, Fapesp, 2007.

LEAL, Claudia F. B. A missão de Michel Parent no Brasil. In: (org.). As missões da Unesco no Brasil: Michel Parent. Rio de Janeiro: IPHAN, COPEDOC, 2008.

MINISTÉRIO DA EDUCAÇÃO E CULTURA. Departamento de Assuntos Culturais. Anais do II Encontro de Governadores. Rio de Janeiro, 1973.

MAYUMI, Lia. Taipa, canela preta e concreto. São Paulo: Romano Guerra Editora, 2008.

MOTTA, Lia. Patrimônio urbano e memória social: práticas discursivas e seletivas de preservação cultural, 1975 a 1990. Dissertação (Mestrado) - Memória Social e Documento / UniRio, Rio de Janeiro, 2000.

MOTTA, Rodrigo Patto Sá. As universidades e o regime militar: cultura política brasileira e modernização autoritária. Rio de Janeiro: Zahar, $2014 \mathrm{a}$.

- A modernização autoritário-conservadora nas universidades e a influência da cultura política. In: REIS FILHO, Daniel Aarão; RIDENTI, Marcelo; MOTTA, Rodrigo Patto Sá. A ditadura que mudou o Brasil: 50 anos do golpe militar de 1964. Rio de Janeiro: Zahar, $2014 \mathrm{~b}$.

PEREIRA, Juliana Melo. “Admiráveis insensatos": Ayrton Carvalho, Luís Saia e as práticas no campo da conservação no Brasil. Dissertação (Mestrado) - Programa de pós-graduação em Desenvolvimento Urbano / UFPE, Recife, 2012.

RAMALHO, Arthur Dias Soares. Planejamento e preservação: a Fundação João Pinheiro e Plano de Conservação, Valorização e Desenvolvimento de Ouro Preto e Mariana. Dissertação (Mestrado) - Instituto de Arquitetura e Urbanismo / USP, São Carlos, 2015.

REIS FILHO, Daniel Aarão; MOTTA, Rodrigo Patto Sá; RIDENTI, Marcelo. A ditadura que mudou o Brasil: 50 anos do golpe militar de 1964. Rio de Janeiro: Zahar, 2014a.

REIS, Daniel Aarão. As marcas do período. In: (coord.) História do Brasil Nação: 1808-2010. V.5, Modernização, ditadura e democracia, 1964-2000. Rio de Janeiro: Objetiva, 2014b, p. 23-29.

RODRIGUES, Marly. Imagens do passado: a instituição do patrimônio em São Paulo, 19691987. São Paulo: Unesp/Imprensa Oficial do Estado / Condephaat/Fapesp, 2000. 
SANTOS, Mariza Veloso. Nasce a academia SPHAN. Revista do Patrimônio Histórico e Artístico Nacional, Rio de Janeiro, n. 24, p. 27-37, 1996.

SODRÉ, João Clark de Abreu. Arquitetura e viagens de formação pelo Brasil (1938-1962). Dissertação (Mestrado) - História e Fundamentos da Arquitetura e do Urbanismo, FAU / USP, São Paulo, 2010.

SOMBRA, Fausto. Luís Saia e o restauro do Sítio Santo Antônio. Diálogos modernos na conformação da arquitetura paulista. Dissertação (Mestrado) - FAU / Mackenzie, São Paulo, 2015.

USP; IAB; DPHAN. Compromisso de Brasília. São Paulo: Universidade de São Paulo, s/d.

TELLES, Augusto Carlos da Silva. Formação de arquitetos para a preservação dos bens culturais. CJ Arquitetura, Rio de Janeiro, n. 17, p. 22-23, 1977.

VARINE-BOHAN, Hughes. Patrimônio cultural: a experiência internacional (Notas de aula, 12.8.1974). São Paulo: FAUUSP/IPHAN, 1975.

URIBARREN, Maria Sabina. Contatos e intercâmbios americanos no IPHAN: o Setor de Recuperação de Obras de Arte (1947-1976). Tese (Doutorado) - História e Fundamentos da Arquitetura e do Urbanismo, FAU / USP, São Paulo, 2015.

\section{DEPOIMENTOS ORAIS A AUTORA}

Dina Lerner, 6 set.2015

Dora Alcântara, 20 out. 2015

Carlos Lemos, 8 out. 2015

Lia Motta, 9 set. 2015

Luiz Eduardo Pinheiro, 19 out. 2015

José Luiz da Mota Meneses, 22 out. 2015

Jurema Kopke Eis Arnaut, 13 nov. 2015

Nestor Goulart Reis Filho, 23 Set. 2015

Sylvia Ficher, 29 set. 2012.

Artigo apresentado em 20/01/2016. Aprovado em 29/04/2016. 